\title{
Cannabinoid Receptor 2 Signalling Bias Elicited by 2,4,6-Trisubstituted 1,3,5-Triazines
} Caitlin R. M. Oyagawa ${ }^{1,2}$, Sara M. de la Harpe ${ }^{3}$, Yurii Saroz
Andrea J. Mernall ${ }^{13}$ and Natasha Lillia Grimsey ${ }^{1,2 *}$

${ }^{1}$ Department of Pharmacology and Clinical Pharmacology, School of Medical Sciences, Faculty of Medical and Health Sciences, The University of Auckland, Auckland, New Zealand, ${ }^{2}$ Centre for Brain Research, School of Medical Sciences, Faculty of Medical and Health Sciences, The University of Auckland, Auckland, New Zealand, ${ }^{3}$ School of Pharmacy, University of Otago, Dunedin, New Zealand

Cannabinoid receptor $2\left(\mathrm{CB}_{2}\right)$ is predominantly distributed in immune tissues and cells and is a promising therapeutic target for modulating inflammation. In this study we designed and synthesised a series of 2,4,6-trisubstituted 1,3,5-triazines with piperazinylalkyl or 1,2-diethoxyethane (PEG2) chains as $\mathrm{CB}_{2}$ agonists, all of which were predicted to be considerably more polar than typical cannabinoid ligands. In this series, we found that triazines containing an adamantanyl group were conducive to $\mathrm{CB}_{2}$ binding whereas those with a cyclopentyl group were not. Although the covalent attachment of a PEG2 linker to the adamantyl triazines resulted in a decrease in binding affinity, some of the ligands produced very interesting $\mathrm{hCB}_{2}$ signalling profiles. Six compounds with notable $\mathrm{hCB}_{2}$ orthosteric binding were functionally characterised in three pathways; internalisation, cyclic adenosine monophosphate (CAMP) and ERK phosphorylation (pERK). These were predominantly confirmed to be $\mathrm{hCB}_{2}$ agonists, and upon comparison to a reference ligand (CP 55,940), four compounds exhibited signalling bias. Triazines 14 (UOSD017) and $\mathbf{1 5}$ were biased towards internalisation over CAMP and $\mathrm{pERK}$, and $\mathbf{7}$ was biased away from pERK activation relative to cAMP and internalisation. Intriguingly, the triazine with an amino-PEG2-piperazinyl linker (13 [UOSD008]) was identified to be a mixed agonist/inverse agonist, exhibiting apparent neutral antagonism in the internalisation pathway, transient inverse agonism in the CAMP pathway and weak partial agonism in the pERK pathway. Both the CAMP and pERK signalling were pertussis toxin (PTX) sensitive, implying that $\mathbf{1 3}$ is acting as both a weak agonist and inverse agonist at $\mathrm{CB}_{2}$ via $\mathrm{G} \alpha_{\mathrm{i} / \mathrm{o}}$. Compound 10 (UOSD015) acted as a balanced high intrinsic efficacy agonist with the potential to produce greater $\mathrm{hCB}_{2}$ mediated efficacy than reference ligand CP 55,940. As 10 includes a Boc-protected PEG2 moiety it is also a promising candidate for further modification, for example with a secondary reporter or fluorophore. The highest affinity compound in this set of relatively polar $\mathrm{hCB}_{2}$ ligands was compound $\mathbf{1 6}$, which acted as a slightly partial balanced agonist in comparison with CP 55,940. The ligands characterised here may therefore exhibit unique functional properties in vivo and have the potential to be valuable in the future development of $\mathrm{CB}_{2}$-directed therapeutics.

Keywords: cannabinoid receptor $2\left(\mathrm{CB}_{2}\right)$, G protein-coupled receptor, signalling bias, signalling, synthetic cannabinoid, drug design, medicinal chemistry, immune therapeutics 


\section{INTRODUCTION}

Cannabinoid receptors $1\left(\mathrm{CB}_{1}\right)$ and $2\left(\mathrm{CB}_{2}\right)$ belong to the $\mathrm{G}$ protein-coupled receptor (GPCR) superfamily, and are the two cannabinoid receptors that have been cloned and characterised to date. $\mathrm{CB}_{1}$ is highly expressed in the central nervous system (CNS) and its function is imperative in many physiological processes including regulation of mood and appetite, pain perception, learning and memory, and motor control (Marsicano and Lutz, 2006; Kano et al., 2009; De Laurentiis et al., 2014), whereas $\mathrm{CB}_{2}$ 's distribution is predominantly in immune tissues and cells (Bouaboula et al., 1993; Galiegue et al., 1995), and it accordingly plays an important role in immunomodulation. At the molecular level, $\mathrm{CB}_{2}$ couples to and signals downstream of $\mathrm{G} \alpha_{\mathrm{i}}$, leading to inhibition of cyclic adenosine monophosphate (cAMP) production via adenylate cyclase and phosphorylation of ERK1/2 (pERK) (Felder et al., 1995; Bouaboula et al., 1996). Downstream effects of $\mathrm{CB}_{2}$ activation include the induction of natural killer cell migration (Kishimoto et al., 2005), regulation of the differentiation of B and T lymphocytes (Ziring et al., 2006), and modulation of cytokine release (Cencioni et al., 2010; Correa et al., 2011). $\mathrm{CB}_{2}$ expression in the $\mathrm{CNS}$ has been reported, particularly in microglia, where its activation was shown to produce anti-inflammatory effects (Ma et al., 2015). $\mathrm{CB}_{2}$ has also been identified in other areas of the body including in osteoblasts and osteoclasts (Ofek et al., 2006), and in the gastrointestinal tract (Atwood and Mackie, 2010), and has thus been indicated as a potential therapeutic target in chronic inflammatory conditions such as osteoporosis (Karsak et al., 2005; Bab and Ofek, 2011) and inflammatory bowel disease (Wright et al., 2005, 2008). There is also potential for $\mathrm{CB}_{2}$ therapeutic intervention in cancers, as receptor and endogenous ligand upregulation has been associated with tumour aggressiveness in some studies (Velasco et al., 2012). Furthermore, due to its largely peripheral distribution, activation of $\mathrm{CB}_{2}$ is not associated with the psychotropic effects that result from $\mathrm{CB}_{1}$ activation, further supporting it as a promising therapeutic target. As such, a focus of recent research efforts has been in developing and evaluating $\mathrm{CB}_{2}$ selective ligands as well as peripherally-restricted $\mathrm{CB}_{1}$ and $\mathrm{CB}_{2}$ ligands.

Phyto- and endo-cannabinoids, as well as the vast majority of synthetic cannabinoids produced to date, possess high wateroctanol partition coefficients $(\log \mathrm{P})$ and are thus inherently highly lipophilic with generally poor pharmacokinetic properties from a drug development perspective (e.g., oral bioavailability) (McGilveray, 2005; Huestis, 2007). A wide range of scaffolds have been reported as $\mathrm{CB}_{2}$ agonists (reviewed by Morales et al., 2016), including those with reduced lipophilicity in comparison with "traditional" cannabinoids which may have improved properties in the context of pharmacological development (e.g., Odan et al., 2012; Yrjölä et al., 2015). $\mathrm{CB}_{2}$ ligands with novel physicochemical properties may also possess unique binding modalities, particularly in comparison with a prevailing theory that ligands can enter the $\mathrm{CB}_{2}$ binding pocket via the lipid bilayer (Hurst et al., 2010). In addition, polar ligands may have reduced access to intracellular receptor populations due to a reduced propensity to cross the plasma membrane in comparison with more lipophilic ligands (Liu et al., 2011). Indeed, $\mathrm{CB}_{2}$ has been reported to be expressed both at the cell surface and intracellularly (Kleyer et al., 2012; Brailoiu et al., 2014; Castaneda et al., 2017), and intracellular $\mathrm{CB}_{2}$ may be able to activate distinct signalling responses from surface $\mathrm{CB}_{2}$ (Brailoiu et al., 2014). Thus ligands that differentiate between these populations would have the potential to induce differential signalling patterns in comparison with lipophilic ligands that can interact with both surface and intracellular receptors. Furthermore, an increase in $\mathrm{CB}_{2}$ ligand polarity can restrict blood-brain barrier permeability and therefore entry to the CNS (van der Stelt et al., 2011; Odan et al., 2012), which could also be therapeutically advantageous.

An additional motivation in designing ligand scaffolds with increased polarity and/or hydrophilic chains is in preparation for conjugation to fluorophores, i.e., fluorescent ligands, and other functional groups which can be valuable tools in characterising receptor localisation and function (Stoddart et al., 2015). As a prerequisite for making such ligands, it is necessary to investigate which chemical groups on a scaffold can be modified whilst retaining affinity and functional activity at the receptor of interest.

Recently, a set of 2,4,6-trisubstituted 1,3,5-triazine analogues were reported as potent $\mathrm{CB}_{2}$ agonists (Yrjölä et al., 2013). These analogues are highly lipophilic, and as such Yrjölä et al. (2015) commented that these compounds may have limited applicability in vivo. To address this, Yrjölä et al. (2015) synthesised a revised set of 2,4,6-trisubstituted 1,3,5-triazine analogues with polar functional groups with overall decreased lipophilicity and increased water solubility. In this study we built further upon this scaffold and synthesised a set of compounds based on the most potent $\mathrm{CB}_{2}$ full agonist reported in the aforementioned study (Yrjölä et al., 2015), 15 in the present manuscript. We synthesised and characterised thirteen 2,4,6-trisubstituted 1,3,5triazine analogues comprised of five previously published $(\mathbf{1}, \mathbf{2}$, $7,15,16)$ and eight novel triazines $(5,6,9-14)$, some of which include linkers for potential fluorophore attachment (Table 1). Compounds which measurably bound to $\mathrm{hCB}_{2}$ (above a predefined cut-off) were assessed for their function via in vitro $\mathrm{hCB}_{2}$ assays (internalisation, cAMP, and pERK). The responses in these pathways were then analysed for signalling bias.

\section{MATERIALS AND METHODS}

\section{Chemistry}

Chemicals were purchased from Sigma Aldrich (St Louis, MO, United States), Merck (Darmstadt, Germany), AK Scientific (Union City, CA, United States), or Ark Pharm, Inc. (Libertyville, IL, United States). Reactions were carried out at room temperature unless otherwise stated. Flash silica gel column chromatography was performed with $40-63 \mu \mathrm{m}$ silica and thin layer chromatography with $0.2 \mathrm{~mm}$ aluminium-backed silica gel plates $60 \mathrm{~F}_{254}$ using UV light, ninhydrin and/or $\mathrm{KMnO}_{4}$. An Agilent 1260 Infinity system (Santa Clara, CA, United States) was used for reverse phase high-performance liquid chromatography (RP-HPLC), with a C8 $5 \mu \mathrm{m}(150 \times 10 \mathrm{~mm})$ semi-preparative 
or C8 $5 \mu \mathrm{m}(150 \times 4.6 \mathrm{~mm})$ analytical column (YMC, Kyoto, Japan). RP-HPLC solvents were A: $\mathrm{H}_{2} \mathrm{O}(0.05 \%$ TFA) and B: 9:1 MeCN:H $\mathrm{H}_{2} \mathrm{O}$ (0.05\% TFA). Analytical RP-HPLC retention times are given using - 5\% solvent B $1 \mathrm{~min}$, gradient of 5-95\% solvent B 1-27 min, 95\% solvent B 27$28 \mathrm{~min}$, gradient of $95-5 \%$ solvent B $28-30 \mathrm{~min}, 5 \%$ solvent B 30-34 min. Purities were assessed by analytical RP-HPLC analysis at 254 and $380 \mathrm{~nm}$. Compound purities are given for all test compounds as a \% purity via peak integration at $254 \mathrm{~nm}$. TFA salts of RP-HPLC purified compounds were neutralised using an Amberlyst A21 ion exchange resin before biological testing. High resolution electrospray ionisation mass spectroscopy (HRMS-ESI) was carried out using a Bruker micrOTOF mass spectrometer (Bruker, Billerica, MA, United States). NMR spectra were obtained using a Varian 400-MR or $500 \mathrm{MHz}$ AR premium shielded spectrometer (Varian, Palo Alto, CA, United States). Chemical shifts are listed in ppm $(\delta)$, calibrated using residual undeuterated solvent, and coupling constants $(J)$ are recorded in hertz $(\mathrm{Hz})$. clogP and $\operatorname{cog} \mathrm{D}_{7.4}$ were calculated in MarvinSketch (version 17.6.0, ChemAxon) using the "ChemAxon" calculation method and the default electrolyte concentration $\left(\mathrm{Cl}^{-} 0.1 \mathrm{~mol} / \mathrm{dm}^{3}, \mathrm{Na}^{+} \mathrm{K}^{+}\right.$ $\left.0.1 \mathrm{~mol} / \mathrm{dm}^{3}\right)$.

4-Chloro-N-cyclopentyl-6-ethoxy-1,3,5-triazin-2-amine 1 and $N$-cyclopentyl-4-ethoxy-6-(piperazin-1-yl)-1,3,5-triazin-2-amine 2 were prepared as previously reported (Yrjölä et al., 2013, 2015). $\mathbf{1}$ and $\mathbf{2}$ were characterised by NMR spectroscopy and HRMS (data not shown), and sample purity of test compounds was 97.3 and $100 \%$, respectively.

\section{tert-Butyl N-(6-(4-(4-(Cyclopentylamino)-6-Ethoxy- 1,3,5-Triazin-2-yl)Piperazin-1-yl)Hexyl)Carbamate (3)}

A mixture of 2 (0.12 g, $0.41 \mathrm{mmol})$, tert-butyl $\mathrm{N}$-(6-bromohexyl) carbamate $(0.12 \mathrm{~g}, 0.41 \mathrm{mmol}), \mathrm{K}_{2} \mathrm{CO}_{3}(0.17 \mathrm{~g}, 1.23 \mathrm{mmol})$, and $\mathrm{NaI}(2 \mathrm{mg})$ in dioxane $(30 \mathrm{~mL})$ was refluxed for $24 \mathrm{~h}$. The solvent was removed under reduced pressure and the residue diluted with $\mathrm{CH}_{2} \mathrm{Cl}_{2}$ and washed with water. The organic layer was dried with $\mathrm{MgSO}_{4}$, the solvent concentrated under reduced pressure and purified by silica gel flash chromatography (100\% EtOAc) to give $3\left(0.15 \mathrm{~g}, 0.30 \mathrm{mmol}, 72 \%\right.$ yield) as a yellow oil. ${ }^{1} \mathrm{H}$ NMR $\left(400 \mathrm{MHz}, \mathrm{CDCl}_{3}\right) \delta 1.32-1.72(\mathrm{~m}, 17 \mathrm{H}), 1.44(\mathrm{~s}, 9 \mathrm{H}), 2.00(\mathrm{~m}$, $2 \mathrm{H}), 2.38-2.55$ (br m, 6H), $3.11(\mathrm{~m}, 2 \mathrm{H}), 3.84(\mathrm{~m}, 4 \mathrm{H}), 4.29$ (m, 2H), 4.51 (br s, $1 \mathrm{H}), 4.95$ (br s, $1 \mathrm{H}) .{ }^{13} \mathrm{C} \mathrm{NMR}(101 \mathrm{MHz}$, $\left.\mathrm{CDCl}_{3}\right) \delta 14.5,23.7,26.3,26.6,27.1,28.4,30.0,33.2,40.4,42.8$, $52.5,52.9,58.5,62.2,78.9,156.0,165.9,166.5,170.4$. HRMS (m/z): $[\mathrm{M}+\mathrm{H}]^{+}$calcd. for $\mathrm{C}_{25} \mathrm{H}_{46} \mathrm{~N}_{7} \mathrm{O}_{3}, 492.3657$; found, 492.3624 .

\section{tert-Butyl N-(2-(2-(2-(4-(4-(Cyclopentylamino)-6- Ethoxy-1,3,5-Triazin-2-yl)Piperazin-1-yl)Ethoxy) Ethyl)Carbamate (4)}

2 (85.0 $\mathrm{mg}, 0.29 \mathrm{mmol}$ ) and tert-butyl $N$-\{2-[2-(2-bromoethoxy) ethoxy] ethyl $\}$ carbamate $(85.0 \mathrm{mg}, 0.29 \mathrm{mmol})$ were reacted according to the procedure for 3 and purified by silica gel flash chromatography $\left(5 \% \mathrm{MeOH} / \mathrm{CH}_{2} \mathrm{Cl}_{2}\right)$ to give $4(100.0 \mathrm{mg}$, $0.19 \mathrm{mmol}, 66 \%$ yield) as a pale yellow oil. ${ }^{1} \mathrm{H} \mathrm{NMR}(400 \mathrm{MHz}$, $\left.\mathrm{CDCl}_{3}\right) \delta 1.35(\mathrm{~m}, 3 \mathrm{H}), 1.40-1.46(\mathrm{~m}, 11 \mathrm{H}), 1.61(\mathrm{~m}, 2 \mathrm{H}), 1.70$ $(\mathrm{m}, 2 \mathrm{H}), 2.00(\mathrm{~m}, 2 \mathrm{H}), 2.77-2.90$ (br m, 6H), $3.31(\mathrm{~m}, 2 \mathrm{H}), 3.53$ $(\mathrm{t}, J=5.2 \mathrm{~Hz}, 2 \mathrm{H}), 3.61(\mathrm{~m}, 4 \mathrm{H}), 3.81(\mathrm{~m}, 2 \mathrm{H}), 3.99(\mathrm{~m}, 4 \mathrm{H})$, 4.25 - 4.36 (br m, 3H), 5.07 (br s, $1 \mathrm{H}), 5.13$ (br s, $1 \mathrm{H}) .{ }^{13} \mathrm{C} \mathrm{NMR}$ $\left(101 \mathrm{MHz}, \mathrm{CDCl}_{3}\right) \delta 14.6,23.7,28.5,33.3,33.4,40.4,42.9,52.5$, 53.4, 57.9, 62.4, 68.5, 70.3, 70.4, 70.4, 79.3, 156.1, 166.0, 166.6, 170.5. HRMS (m/z): $[\mathrm{M}+\mathrm{H}]^{+}$calcd. for $\mathrm{C}_{25} \mathrm{H}_{46} \mathrm{~N}_{7} \mathrm{O}_{5}, 524.3555$; found, 524.3511 .

\section{4-(4-(6-Aminohexyl)Piperazin-1-yl)-N-Cyclopentyl- 6-Ethoxy-1,3,5-Triazin-2-Amine (5, UOSD005)}

$3(3.0 \mathrm{mg}, 6.1 \mu \mathrm{mol})$ was dissolved in $\mathrm{CH}_{2} \mathrm{Cl}_{2}(0.5 \mathrm{~mL})$ and trifluoroacetic acid $(0.25 \mathrm{~mL})$ was added. After $1 \mathrm{~h}$ the solvents were evaporated and the product purified by semipreparative RP-HPLC and then neutralised using Amberlyst A21 ion exchange resin to give $5(2.3 \mathrm{mg}, 5.9 \mu \mathrm{mol}, 96 \%$ yield $)$ as a waxy, white solid. HRMS $(\mathrm{m} / \mathrm{z}):[\mathrm{M}+\mathrm{H}]^{+}$calcd. for $\mathrm{C}_{20} \mathrm{H}_{38} \mathrm{~N}_{7} \mathrm{O}$, 392.3132; found, 392.3104. Analytical RP-HPLC $R_{\mathrm{t}}=10.72$ min, purity $100 \%$.

\section{4-(4-(2-(2-(2-Aminoethoxy)Ethoxy)Ethyl)Piperazin-1- yl)-N-Cyclopentyl-6-Ethoxy-1,3,5-Triazin-2-Amine (6, UOSD009)}

$4(10.0 \mathrm{mg}, 19.1 \mu \mathrm{mol})$ was reacted according to the procedure for 5 to give $\mathbf{6}(6.3 \mathrm{mg}, 13.5 \mu \mathrm{mol}, 78 \%$ yield $)$ as a yellow oil. HRMS $(\mathrm{m} / \mathrm{z}):[\mathrm{M}+\mathrm{H}]^{+}$calcd. for $\mathrm{C}_{20} \mathrm{H}_{38} \mathrm{~N}_{7} \mathrm{O}_{3}, 424.3031$; found, 424.3037. Analytical RP-HPLC $R_{\mathrm{t}}=10.27 \mathrm{~min}$, purity $96.2 \%$.

$N$-(ad-amantan-1-yl)-4-ethoxy-6-(piperazin-1-yl)-1,3,5-triazi n-2-amine 7, N-(Adamantan-1-yl)-4-ethoxy-6-(4-methylpipera zin-1-yl)-1,3,5-triazin-2-amine 15, and $N$-(adamantan-1-yl)-4-et hoxy-6-(4-(2-fluoroethyl) piperazin-1-yl)-1,3,5-triazin-2-amine 16 were prepared as previously reported (Yrjölä et al., 2013, 2015). 7, 15, and 16 were characterised by NMR spectroscopy and HRMS (data not shown), and sample purity of test compounds was $97.2,99.5$, and $98.5 \%$, respectively.

\section{tert-Butyl N-(2-(4-(4-((Adamantan-1-yl)Amino)- 6-Ethoxy-1,3,5-Triazin-2-yl)Piperazin-1-yl)Ethyl) Carbamate (8)}

7 (120 mg, $0.33 \mathrm{mmol}$ ) and 2-(Boc-amino) ethyl bromide (120.0 $\mathrm{mg}, 0.54 \mathrm{mmol}$ ) were reacted according to the procedure for 3 and purified by silica gel flash chromatography (5\% $\mathrm{MeOH} / \mathrm{CH}_{2} \mathrm{Cl}_{2}$ ) to give a $\sim 2: 1$ mixture of 8 and the Bocdeprotected analogue of $\mathbf{8}(25 \mathrm{mg})$. Since $\mathbf{8}$ was not analysed for biological activity, the $\sim 2: 1$ mixture was carried through to the Boc-deprotection reaction (11, described later) (with NMR data reported for 11).

\section{tert-Butyl N-(6(4-(4-(Adamantan-1-yl)Amino)- 6-Ethoxy-1,3,5-Triazin-2-yl)Piperazin-1-yl)Hexyl) Carbamate (9, UOSD016)}

7 (120 mg, $0.33 \mathrm{mmol}$ ) and tert-butyl $N$-(6-bromohexyl) carbamate $(90 \mathrm{mg}, 0.32 \mathrm{mmol})$ were reacted according to the procedure for 3 and purified by silica gel flash chromatography (50-80\% EtOAc/hexane) to give 9 ( $82 \mathrm{mg}, 0.15 \mathrm{mmol}, 44 \%$ yield) as a pale yellow oil. ${ }^{1} \mathrm{H}$ NMR $\left(400 \mathrm{MHz}, \mathrm{CDCl}_{3}\right) \delta 1.32(\mathrm{~m}$, $7 \mathrm{H}), 1.41-1.53(\mathrm{~m}, 11 \mathrm{H}), 1.68(\mathrm{~m}, 8 \mathrm{H}), 2.08(\mathrm{~m}, 9 \mathrm{H}), 2.33(\mathrm{t}$, $J=6.7 \mathrm{~Hz}, 2 \mathrm{H}), 2.43(\mathrm{~m}, 4 \mathrm{H}), 3.10(\mathrm{~m}, 2 \mathrm{H}), 3.79(\mathrm{~m}, 4 \mathrm{H}), 4.28$ $(\mathrm{m}, 2 \mathrm{H}), 4.51$ (br s, $1 \mathrm{H}), 4.88$ (br s, $1 \mathrm{H}) .{ }^{13} \mathrm{C}$ NMR $\left(\mathrm{CDCl}_{3}\right) \delta$ 
$14.7,26.8,27.3,28.6,29.6,30.1,36.6,36.7,40.7,42.0,43.3,51.5$, 53.2, 58.8, 62.5, 79.1, 156.1, 161.0, 165.8, 170.5. HRMS (m/z): $[\mathrm{M}+\mathrm{H}]^{+}$calcd. for $\mathrm{C}_{30} \mathrm{H}_{52} \mathrm{~N}_{7} \mathrm{O}_{3}, 558.4126$; found, 558.4107 . Analytical RP-HPLC $R_{\mathrm{t}}=18.96 \mathrm{~min}$, purity $100 \%$.

tert-Butyl N-(2-(2-(2-(4-(4-((Adamantan-1-yl)Amino)6-Ethoxy-1,3,5-Triazin-2-yl)Piperazin-1-yl)Ethoxy) Ethoxy)Ethyl)Carbamate (10, UOSD015)

7 (80.0 $\mathrm{mg}, 0.22 \mathrm{mmol}$ ) and tert-butyl $N$ - $\{2$-[2-(2-bromoethoxy) ethoxy] ethyl $\}$ carbamate $(70.0 \mathrm{mg}, 0.23 \mathrm{mmol})$ were reacted according to the procedure for 3 and purified by silica gel flash chromatography ( $\left.5 \% \mathrm{MeOH} / \mathrm{CH}_{2} \mathrm{Cl}_{2}\right)$ to give $10(73 \mathrm{mg}$, $0.12 \mathrm{mmol}, 55 \%$ yield) as a pale yellow oil. ${ }^{1} \mathrm{H}$ NMR $(400 \mathrm{MHz}$, $\left.\mathrm{CDCl}_{3}\right) \delta 1.33,(\mathrm{~m}, 3 \mathrm{H}), 1.42(\mathrm{~s}, 9 \mathrm{H}), 1.66(\mathrm{~m}, 6 \mathrm{H}), 2.05$ (br m, $9 \mathrm{H}), 2.59(\mathrm{~m}, 4 \mathrm{H}), 2.68(\mathrm{~m}, 2 \mathrm{H}), 3.29(\mathrm{~m}, 2 \mathrm{H}), 3.51(\mathrm{~m}, 2 \mathrm{H}), 3.59$ (m, $4 \mathrm{H}), 3.67(\mathrm{~m}, 2 \mathrm{H}), 3.84(\mathrm{~m}, 4 \mathrm{H}), 4.26(\mathrm{~m}, 2 \mathrm{H}), 4.92$ (br s, $1 \mathrm{H})$, 5.11 (br s, $1 \mathrm{H}) .{ }^{13} \mathrm{C} \mathrm{NMR}\left(101 \mathrm{MHz}, \mathrm{CDCl}_{3}\right) \delta 14.7,28.5,29.6$, 36.6, 40.5, 41.9, 42.8, 51.6, 53.4, 57.8, 62.3, 68.3, 70.3, 70.4, 70.4, 79.3, 156.1, 165.7, 166.1, 170.4. HRMS (m/z): $[\mathrm{M}+\mathrm{H}]^{+}$calcd. for $\mathrm{C}_{30} \mathrm{H}_{52} \mathrm{~N}_{7} \mathrm{O}_{5}, 590.4024$; found, 590.3974. Analytical RP-HPLC $R_{\mathrm{t}}=18.69 \mathrm{~min}$, purity $96.9 \%$.

\section{N-(Adamantan-1-yl)-4-(4-(2-Aminoethyl)Piperazin-1-} yl)-6-Ethoxy-1,3,5-Triazin-2-Amine (11, UOSD007)

$8(10 \mathrm{mg}, 19.9 \mu \mathrm{mol})$ was reacted according to the procedure for 5 to give 11 as a white waxy solid ( $5.4 \mathrm{mg}, 13.45 \mu \mathrm{mol}, 67 \%$ yield). ${ }^{1} \mathrm{H}$ NMR (400 MHz, CD $\left.3 \mathrm{OD}\right) \delta 1.38(\mathrm{t}, J=7.1 \mathrm{~Hz}, 3 \mathrm{H}), 1.74(\mathrm{~m}$, $6 \mathrm{H}), 2.10(\mathrm{~m}, 3 \mathrm{H}), 2.14(\mathrm{~m}, 6 \mathrm{H}), 2.69(\mathrm{~m}, 4 \mathrm{H}), 2.76(\mathrm{~m}, 2 \mathrm{H}), 3.14$ (m, 2H), 3.94 (br m, 4H), $4.46(\mathrm{~m}, 2 \mathrm{H})$. HRMS (m/z): $[\mathrm{M}+\mathrm{H}]^{+}$ calcd. for $\mathrm{C}_{21} \mathrm{H}_{36} \mathrm{~N}_{7} \mathrm{O}, 402.2976$; found, 402.2961. Analytical RPHPLC $R_{\mathrm{t}}=14.12 \mathrm{~min}$, purity $97.1 \%$.

\section{$N$-(Adamantan-1-yl)-4-(4-(6-Aminohexyl)Piperazin-1- yl)-6-Ethoxy-1,3,5-Triazin-2-Amine (12, UOSD010)}

9 (13 mg, $23.3 \mu \mathrm{mol})$ was reacted according to the procedure for 5 to give 12 as a white waxy solid (9.2 mg, $20.1 \mu$ mol, $86 \%$ yield). HRMS (m/z): $[\mathrm{M}+\mathrm{H}]^{+}$calcd. for $\mathrm{C}_{25} \mathrm{H}_{44} \mathrm{~N}_{7} \mathrm{O}, 458.3602$; found, 458.3612. Analytical RP-HPLC $R_{\mathrm{t}}=14.50 \mathrm{~min}$, purity $100 \%$.

\section{$\mathrm{N}$-(Adamantan-1-yl)-4-(4-(2-(2-(2-Aminoethoxy) Ethoxy)Ethyl)Piperazin-1-yl)-6-Ethoxy-1,3,5-Triazin- 2-Amine (13, UOSD008)}

$10(10.0 \mathrm{mg}, 17.0 \mu \mathrm{mol})$ was reacted according to the procedure for 5 to give $13(8.0 \mathrm{mg}, 16.3 \mu \mathrm{mol}, 96 \%$ yield $)$ as a white waxy solid. ${ }^{1} \mathrm{H}$ NMR (400 MHz, CD $\left.\mathrm{CD}_{3} \mathrm{OD}\right) \delta 1.37$, (t, $\left.J=6.9 \mathrm{~Hz}, 3 \mathrm{H}\right)$, $1.74(\mathrm{~m}, 6 \mathrm{H}), 2.10$ (br m, 2H), 2.14 (br m, 7H), 3.12 (t, $J=5.1 \mathrm{~Hz}$, $2 \mathrm{H}), 3.34(\mathrm{~m}, 4 \mathrm{H}), 3.40$ - 3.51 (br m, 6H), $3.71(\mathrm{~m}, 6 \mathrm{H})$, $3.87(\mathrm{~m}, 2 \mathrm{H}), 4.44(\mathrm{~m}, 2 \mathrm{H}) .{ }^{13} \mathrm{C} \mathrm{NMR}\left(101 \mathrm{MHz}, \mathrm{CD}_{3} \mathrm{OD}\right) \delta$ 14.54, 30.94, 37.45, 40.55, 41.84, 42.40, 49.85, 52.80, 53.78, 57.54, $65.53,67.86,71.29,71.35,162.69,163.05,165.59$. HRMS (m/z): $[\mathrm{M}+\mathrm{H}]^{+}$calcd. for $\mathrm{C}_{25} \mathrm{H}_{44} \mathrm{~N}_{7} \mathrm{O}_{3}, 490.3500$; found, 490.3478 . Analytical RP-HPLC $R_{\mathrm{t}}=13.47 \mathrm{~min}$, purity $100 \%$.

\section{N-(2-(2-(2-(4-(4-((Adamantan-1-yl)Amino)-6-Ethoxy- 1,3,5-Triazin-2-yl)Piperazin-1-yl)Ethoxy)Ethoxy) Ethyl)Acetamide (14, UOSD017)}

To a solution of $13(10.0 \mathrm{mg}, 20.4 \mu \mathrm{mol})$ in $\mathrm{CH}_{2} \mathrm{Cl}_{2}(1 \mathrm{~mL})$ was added $\mathrm{Et}_{3} \mathrm{~N}(8 \mu \mathrm{L}, 61 \mu \mathrm{mol})$ and acetic anhydride $(2 \mu \mathrm{L}$,
$22 \mu \mathrm{mol})$. After $30 \mathrm{~min}$, the solvents were removed and the product was purified by semi-preparative RP-HPLC to give $\mathbf{1 4}$ (4.0 mg, $7.5 \mu \mathrm{mol}, 37 \%$ yield) as a white waxy solid. HRMS (m/z): $[\mathrm{M}+\mathrm{H}]^{+}$calcd. for $\mathrm{C}_{27} \mathrm{H}_{46} \mathrm{~N}_{7} \mathrm{O}_{4}$, 532.3606; found, 532.3571 . Analytical RP-HPLC $R_{\mathrm{t}}=15.53 \mathrm{~min}$, purity $100 \%$.

\section{Cell Lines and Maintenance}

Cell culture medium and reagents were purchased from Thermo Fisher Scientific (Waltam, MA, United States), and plasticware was purchased from Corning (Corning, NY, United States) unless otherwise noted. HEK Flp-in wild-type (wt) cells were purchased from Invitrogen (Carlsbad, CA, United States). HEK Flp-in $\mathrm{hCB}_{2}$ and wt lines were maintained in high glucose Dulbecco's Modified Eagle's Medium (DMEM, Thermo Fisher Scientific medium formulation \#11995) supplemented with 10\% foetal bovine serum (FBS, New Zealand-origin, Moregate Biotech, Brisbane, Australia) and appropriate selection antibiotics, and incubated in $5 \% \mathrm{CO}_{2}$ at $37^{\circ} \mathrm{C}$ in a humidified atmosphere. The HEK Flp-in line stably expressing $\mathrm{hCB}_{2}$ with an aminoterminal haemagglutinin (HA) tag has been described previously (Soethoudt et al., 2017, see pERK assay).

\section{Radioligand Binding Assays}

The $\mathrm{hCB}_{2}$-expressing $\mathrm{HEK}$ cell line used for binding assays was first reported in Grimsey et al. (2011), and the $\mathrm{hCB}_{1}$ expressing HEK cell line was first reported in Finlay et al. (2017). Cells were harvested and membranes prepared as described previously (Finlay et al., 2017) and subsequently homologous and heterologous competition assays were performed. $\left[{ }^{3} \mathrm{H}\right]$ CP 55,940 (final concentration $0.5 \mathrm{nM}$ for $\mathrm{hCB}_{2}$ and $0.75 \mathrm{nM}$ for $\mathrm{hCB}_{1}$; PerkinElmer, Waltham, MA, United States), HEK membranes $\left(2.25 \mu \mathrm{g}\right.$ per point for $\mathrm{hCB}_{2}$ and $2.5 \mu \mathrm{g}$ per point for $\mathrm{hCB}_{1}$ ), concentration series of CP 55,940 (Tocris, Bristol, United Kingdom) for homologous competition assays to obtain $\mathrm{K}_{\mathrm{d}}$ and concentration series or single concentrations of 2,4,6trisubstituted 1,3,5-triazines for heterologous competition assays to obtain $\mathrm{K}_{\mathrm{i}} \mathrm{s}$ at $\mathrm{hCB}_{2}$ or to determine binding extent at $10 \mu \mathrm{M}$ at $\mathrm{hCB}_{1}$, respectively, were individually prepared in binding buffer (50 mM HEPES pH 7.4, $1 \mathrm{mM} \mathrm{MgCl}_{2}, 1 \mathrm{mM} \mathrm{CaCl}$, $2 \mathrm{mg} \mathrm{mL}^{-1}$ low endotoxin bovine serum albumin; BSA, ICPBio, Auckland, New Zealand), and incubated together for $1 \mathrm{~h}$ at $30^{\circ} \mathrm{C}$. A 96-well Harvest Plate (PerkinElmer) was pre-soaked with $0.1 \% \mathrm{wv}^{-1}$ polyethylenimine (PEI; Sigma-Aldrich) for $1 \mathrm{~h}$ at room temperature, and at the end of the incubation placed on a vacuum manifold and washed with $200 \mu \mathrm{L}$ ice-cold wash buffer (50 mM HEPES pH 7.4, $500 \mathrm{mM} \mathrm{NaCl}, 1 \mathrm{mg} \mathrm{mL}^{-1}$ BSA). Immediately following this, samples were transferred onto the harvest plate and subjected to a further three $200 \mu \mathrm{L}$ washes with ice-cold wash buffer. Harvest plates were dried overnight, followed by the addition of $50 \mu \mathrm{L}$ Irga-Safe Plus scintillation fluid (PerkinElmer) to each well. Controls to verify that radioligand depletion was less than $10 \%$ were also included. After a $30 \mathrm{~min}$ delay, plates were detected for 2 min per well in a MicroBeta ${ }^{\circledR}$ TriLux (PerkinElmer). Homologous competition assays were utilised to determine $\mathrm{K}_{\mathrm{d}}$ at $\mathrm{hCB}_{2}$ for CP 55,940 and conformed to homologous binding assumptions (Motulsky and Christopoulos, 2003). Both homologous and heterologous binding data were 
modelled utilising predefined equations in GraphPad Prism (v7.03; GraphPad Software Inc., La Jolla, CA, United States). In heterologous binding assays, curves were constrained for compounds that did not fully displace $\left[{ }^{3} \mathrm{H}\right]-\mathrm{CP} 55,940$, whereby the bottom of the curve was defined by maximum CP 55,940 displacement of $\left[{ }^{3} \mathrm{H}\right]$-CP 55,940 .

\section{Internalisation Assays}

Internalisation assays were carried out by fluorescent immunocytochemistry with selective antibody labelling of cell surface receptors as described previously with minor modifications (Grimsey et al., 2008, 2011). In brief, HEK Flp-in $\mathrm{hCB}_{2}$ cells were seeded at $4.5 \times 10^{4}$ cells/well in poly-D-lysine (Sigma-Aldrich) treated clear 96-well Nunc ${ }^{\mathrm{TM}}$ plates (Thermo Fisher Scientific) $18-24 \mathrm{~h}$ prior to stimulation. All drugs and reagents for internalisation assays were prepared in high glucose DMEM supplemented with $1 \mathrm{mg} \mathrm{mL}^{-1}$ BSA (basal medium). Cells were equilibrated in basal medium for $30 \mathrm{~min}$ at $37^{\circ} \mathrm{C}$, and incubated with anti-mouse monoclonal HA.11 (901503; BioLegend, San Diego, CA, United States) diluted 1:500 in basal medium for $30 \mathrm{~min}$ at room temperature (thereby restricting primary antibody labelling to cell surface $\mathrm{hCB}_{2}$ ). Cells were then briefly washed with basal medium and then incubated with vehicle or drug for $1 \mathrm{~h}$ at $37^{\circ} \mathrm{C}$. At the conclusion of the drug incubation, plates were placed on ice for at least $2 \mathrm{~min}$ to halt membrane trafficking and briefly washed with room temperature basal medium. Alexa Fluor ${ }^{\circledR}$ 488-conjugated goat anti-mouse secondary antibody (Invitrogen) diluted 1:300 in basal medium was then applied to cells and incubated for $30 \mathrm{~min}$ at room temperature (thereby restricting secondary antibody labelling to only residual primary antibody-bound $\mathrm{hCB}_{2}$ remaining on the cell surface at the end of drug treatment). Cells were then washed twice with basal medium and fixed in $4 \%$ paraformaldehyde for $10 \mathrm{~min}$. Following two phosphate buffered saline (PBS) washes, cell nuclei were labelled with Hoechst $33258\left(4 \mathrm{mg} \mathrm{mL}^{-1}\right.$ in water; Sigma-Aldrich) diluted 1:500 in PBS with $0.2 \%$ Triton $\mathrm{X}-100$.

Image acquisition and analysis were based on previously described methods (Grimsey et al., 2008; Finlay et al., 2016). Briefly, images were captured with the ImageXpress ${ }^{\circledR}$ Micro XLS Widefield High-Content Analysis System (Molecular Devices, Sunnyvale, CA, United States) $(10 \times$ objective, 4 sites per well), and receptor internalisation quantified using MetaXpress ${ }^{\circledR}$ software (v6.2.3.733, Molecular Devices) by calculating the fluorescence intensity per cell above background. Data were normalised to vehicle-treated (100\%).

\section{cAMP Assays}

Cellular cAMP levels were measured using a real-time BRET biosensor (CAMYEL) as previously described (Cawston et al., 2013). In brief, cells were seeded in $10 \mathrm{~cm}$ dishes one day prior to transfection. The medium was then replaced and cells transfected with $5 \mu \mathrm{g}$ of pcDNA3L-His-CAMYEL (ATCC, Manassas, VA, United States) using linear PEI (MW $25 \mathrm{kDa}$; Polysciences, Warrington, PA, United States) with a DNA:PEI ratio of 1:6. Approximately $24 \mathrm{~h}$ after transfection, cells were trypsinised and re-plated in poly-D-lysine treated white 96well plates (Corning), at a density of 5-6 $\times 10^{4}$ cells per well. For experiments involving pertussis toxin (PTX; SigmaAldrich) pre-treatment, cells were seeded in half the usual volume of medium, and then $\sim 5$ h later, $2 \times$ concentrated PTX or vehicle (50\% glycerol, $50 \mathrm{nM}$ Tris- $\mathrm{HCl} \mathrm{pH}$ 7.5, $10 \mathrm{mM}$ glycine, $500 \mathrm{mM} \mathrm{NaCl}$ ) were prepared in medium and added to the existing plating medium (giving rise to a final PTX concentration of $100 \mathrm{ng} \mathrm{mL} \mathrm{m}^{-1}$ ). Approximately $24 \mathrm{~h}$ after plating (or 16$20 \mathrm{~h}$ after applying PTX/vehicle in experiments involving PTX treatment), cells were washed once with Hank's Balanced Salt Solution (HBSS, Thermo Fisher Scientific, catalogue \#14025134), and then equilibrated for $30 \mathrm{~min}$ in HBSS supplemented with $1 \mathrm{mg} \mathrm{mL}^{-1}$ BSA. Coelenterazine $\mathrm{h}$ (final concentration $5 \mu \mathrm{M}$; NanoLight Technologies, Pinetop, AZ, United States) was added to each well and incubated for $5 \mathrm{~min}$. Forskolin was added (final concentration $5 \mu \mathrm{M}$ ) and incubated for 6 min (allowing enough time for the induced cAMP increase to plateau), prior to vehicle/drug addition. All drugs and reagents were prepared in HBSS supplemented with $1 \mathrm{mg} \mathrm{mL}^{-1}$ BSA. SR 144528 was a generous gift from Roche (Basel, Switzerland).

Assays were carried out in technical duplicate. Emissions were detected at $460 \mathrm{~nm}$ (Rluc) and $535 \mathrm{~nm}$ (YFP) with either a LUMIstar ${ }^{\circledast}$ Omega luminometer (BMG Labtech, Ortenberg, Germany) or CLARIOstar ${ }^{\circledR}$ (BMG Labtech). BRET ratios (535 $\mathrm{nm}$ emissions/460 $\mathrm{nm}$ emissions, where an increase in ratio corresponds to a decrease in cAMP) were normalised to pre-forskolin reads (i.e., with coelenterazine $\mathrm{h}$ present) to remove any variability present prior to addition of forskolin and drug/vehicle. A Lowess curve (GraphPad Prism) was fitted to individual technical replicates within an assay so that cAMP signalling data could be extrapolated from any time point as opposed to only those that were empirically measured (typically every 30-60 s). Data were normalised to matched vehicle (0\%) and forskolin (100\%) treatments, allowing compilation of data from independent experiments.

\section{pERK Assays}

ERK phosphorylation assays were performed on HEK Flp-in $\mathrm{hCB}_{2}$ and HEK Flp-in wt cell lines. Cells were seeded at a density of $4.5 \times 10^{4}$ cells per well in poly-D-lysine treated clear 96-well Nunc ${ }^{\mathrm{TM}}$ plates; for PTX experiments cells were plated in the presence of PTX $\left(100 \mathrm{ng} \mathrm{mL} \mathrm{mL}^{-1}\right)$ or vehicle. 24-25 h later, medium was removed and replaced with basal medium (DMEM supplemented with $1 \mathrm{mg} \mathrm{mL}^{-1}$ BSA). Cells were equilibrated for $3 \mathrm{~h}$ at $37^{\circ} \mathrm{C}$ followed by drug stimulations carried out at $37^{\circ} \mathrm{C}$ for $4 \mathrm{~min}$. All drugs were prepared in basal medium at $2 \times$ final concentration. An inhibitor of ERK phosphorylation, U0126 (Cell Signaling Technology, MA, United States) at $10 \mu \mathrm{M}$, and a pERK pathway stimulant, phorbol 12-myristate 13-acetate (PMA; Sigma-Aldrich) at $100 \mathrm{nM}$, both incubated for $15 \mathrm{~min}$, were utilised as reference points. At the conclusion of the drug incubation, plates were placed on ice, and immediately lysed by adding $20 \mu \mathrm{L}$ of ice-cold lysis buffer (from AlphaLISA ${ }^{\circledast}$ Kit; details follow). Detection was performed using the AlphaLISA ${ }^{\circledR}$ SureFire $^{\circledR}$ Ultra $^{\text {TM }}$ p-ERK $1 / 2$ (Thr202/Tyr204) Assay Kit (PerkinElmer), according to manufacturer instructions, 
and plates read in a CLARIOstar ${ }^{\circledR}$ reader (BMG Labtech) using standard AlphaScreen-compatible filters. Data were normalised to matched U0126 (0\%) and PMA (100\%) treatments, allowing compilation of data from independent experiments.

\section{General Analysis and Statistics}

All sigmoidal concentration-response curves were obtained by fitting three-parameter (Hill slope constrained to 1) nonlinear regression curves (GraphPad Prism). Other than for bias analysis (see section "Bias Analysis"), statistical analyses were performed on the means from three to four independent experiments using Sigmaplot ${ }^{\mathrm{TM}}$ v13.0 (Systat Software Inc., San Jose, CA, United States). The Shapiro-Wilk test for normality and BrownForsythe test for equal variance were performed to verify the datasets were appropriate for analysis with parametric statistical tests; all sets obtained a pass result of $p>0.05$. A student's $t$-test, one-way ANOVA, or two-way ANOVA was carried out as appropriate for the number of conditions and factors under comparison, and if a statistically significant difference $(p<0.05)$ was detected, the Holm-Šídák (Shaffer, 1986) post hoc test was used to test for significant differences within/between groups.

\section{Bias Analysis}

Data from independent internalisation, cAMP and pERK experiments were normalised to the vehicle response $(0 \%)$ and the mean maximum response measured for any ligand in that assay $(100 \%)$ so that relative efficacies could be assessed on the same scale. Bias analysis was performed nearly exactly as described by van der Westhuizen et al. (2014) in GraphPad Prism. The derived parameters relating to bias analysis are explained in the results, section 3.6. Methodology, including specific equations for fitting the operational model and subsequently calculating $\Delta \log \mathrm{R}$ and $\Delta \Delta \log \mathrm{R}$ with associated standard errors, were equivalent to this prior publication except that we opted not to subjectively classify ligands into full versus partial agonists (as was done in van der Westhuizen et al., 2014), instead treating all ligands other than the reference as potentially partial (and therefore having the general operational model fitted for all ligands, rather than assuming equivalent efficacy for all qualitatively full agonists). This approach was validated by Zhu et al. (2018), and indeed made no meaningful difference to our own findings when empirically tested. The maximal system efficacy, basal response and " $n$ " (transducer function slope) were set to be "shared for all datasets" as per the default constraints suggested by van der Westhuizen et al. (2014). The mean (and associated error) of all independent CP 55,940 experiments was utilised as the reference condition for comparison with all ligands' independent experiment data analysed separately, including the independent CP 55,940 experiment data which was re-analysed with reference to the mean data in order to obtain an indication of error for this ligand. Tests for statistical significance of differences between $\Delta \Delta \log \mathrm{R}$ values were carried out in GraphPad Prism utilising two-way ANOVA with Holm-Š́dák post hoc multiple comparisons test. $p$-values are indicated graphically as: ${ }^{*}<0.05$, $* *<0.005$, and $* * *<0.001$.

\section{RESULTS}

\section{Chemical Synthesis}

The piperazine-containing 1,3,5-triazines $\mathbf{1}$ and 7 , assembled following literature protocols (compound "26a" in Yrjölä et al., 2013; compound " 8 " in Yrjölä et al., 2015, respectively), were alkylated with various alkyl bromide linkers containing a Boc-protected amine at the terminus to give $\mathbf{3}, \mathbf{4}, \mathbf{8}$, 9 and 10 (Schemes 1, 2). These were then Boc-deprotected using acidic conditions to give primary amines $5,6,11,12$, and 13 .

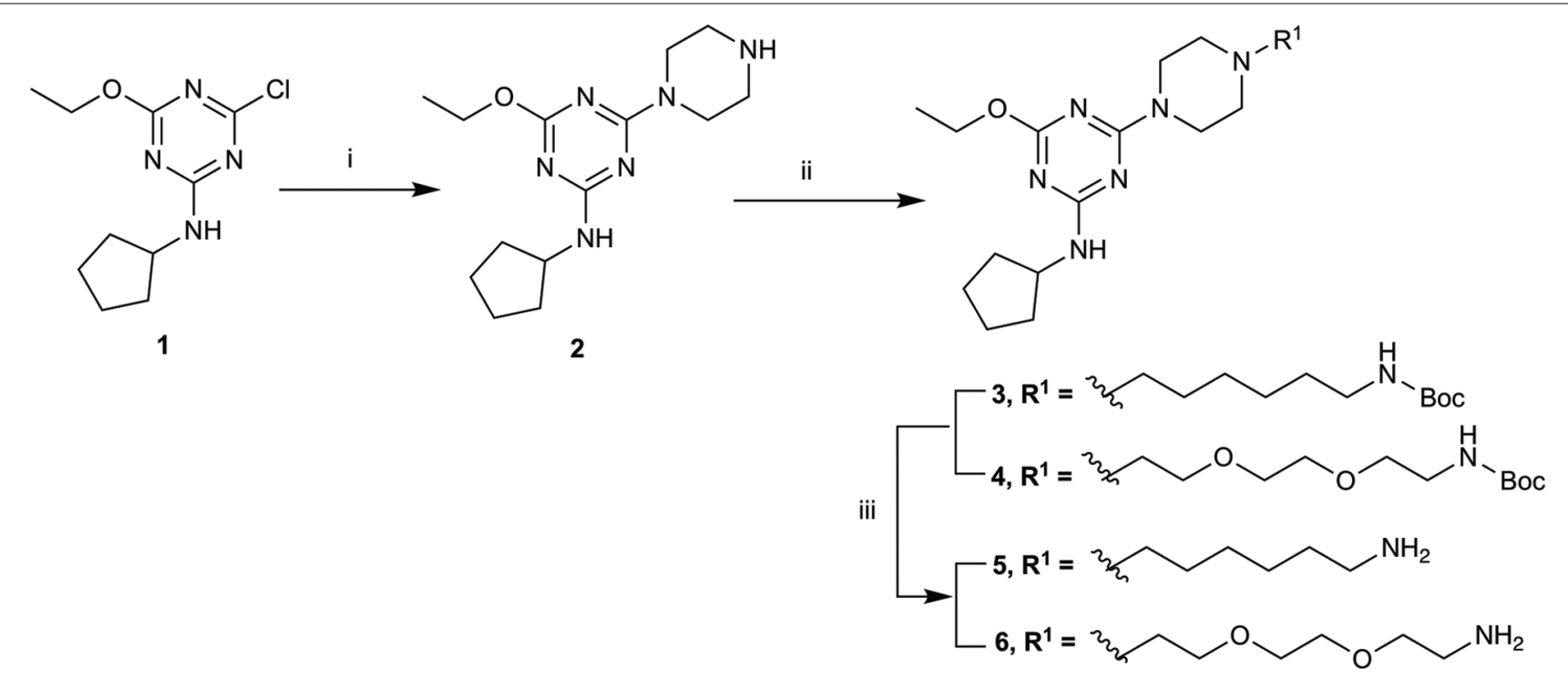

SCHEME 1 | Synthesis of $\mathrm{N}$-cyclopentyl series. (i) piperazine, $\mathrm{N}, \mathrm{N}$-diisopropylethylamine, THF, reflux, $12 \mathrm{~h}, 48 \%$; (ii) tert-butyl $\mathrm{N}$-(6-bromohexyl) carbamate or tert-butyl $\mathrm{N}$-\{2-[2-(2-bromoethoxy)ethoxy]ethyl\}carbamate, $\mathrm{K}_{2} \mathrm{CO}_{3}$, Nal, dioxane, reflux, $24 \mathrm{~h}, 66-72 \%$; and (iii) $\mathrm{CH}_{2} \mathrm{Cl}_{2}$, trifluoroacetic acid, 78-96\%. 


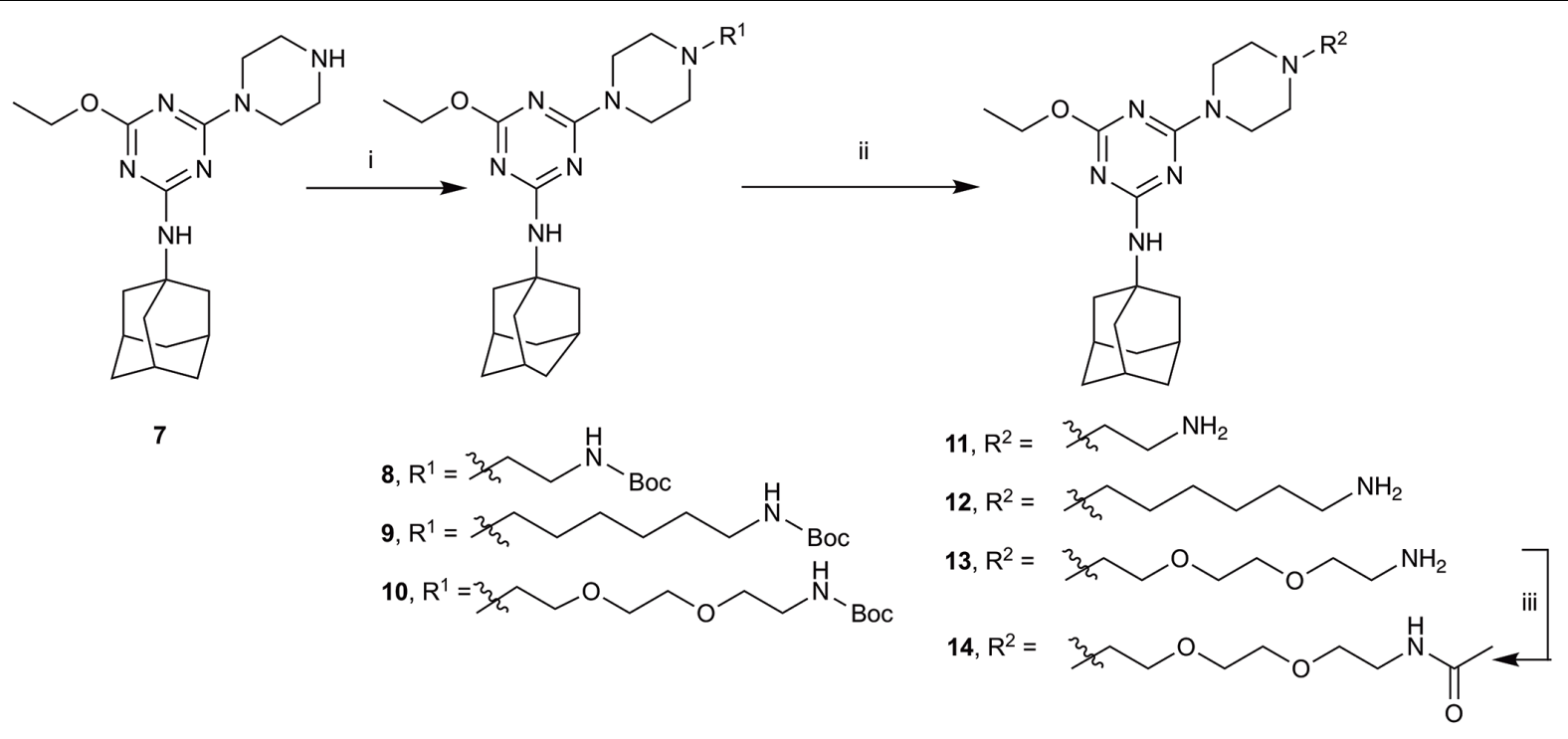

SCHEME 2 | Synthesis of $\mathrm{N}$-adamantanyl series. (i) tert-butyl $\mathrm{N}$-(6-bromohexyl)carbamate or tert-butyl $\mathrm{N}$-\{2-[2-(2-bromoethoxy)ethoxy]ethyl\}carbamate or 2-(Boc-amino)ethyl bromide, $\mathrm{K}_{2} \mathrm{CO}_{3}$, Nal, dioxane, reflux, $24 \mathrm{~h}, 44-55 \%$; (ii) $\mathrm{CH}_{2} \mathrm{Cl}_{2}$, trifluoroacetic acid, $67-96 \%$; and (iii) $\mathrm{CH}_{2} \mathrm{Cl}_{2}$, Et $\mathrm{Et}_{3} \mathrm{~N}$, acetic anhydride, 30 min, $37 \%$.

One example of an acetylated linker (14) was also synthesised. Thirteen compounds were biologically tested (Table 1); five compounds had been reported previously $(1,2,7,15,16)$ (Yrjölä et al., 2013, 2015), and the remainder were novel (5, 6, 9-14). The clogP and $\operatorname{cog} \mathrm{D}_{7.4}$ of the compounds are shown in Table $\mathbf{1}$. Compounds were solubilised in dimethylsulfoxide (DMSO) to produce $31.6 \mathrm{mM}$ stock solutions for pharmacological assays, other than 7 which exhibited a lower solubility in DMSO (to $1 \mathrm{mM}$ ). 7 was therefore assayed in a higher final DMSO content (1\%) than the other compounds $(0.1 \%)$. Both vehicle concentrations were controlled for in all assays (negative/vehicle and positive controls).

\section{Binding Affinity}

CP 55,940, a well characterised synthetic cannabinoid, was utilised in tritiated form as the radioligand to assess orthosteric binding of the compounds of interest to $\mathrm{hCB}_{2} \cdot\left[{ }^{3} \mathrm{H}\right]-\mathrm{CP} 55,940$ was measured to have a $\mathrm{pK}_{\mathrm{d}}$ of $8.89( \pm 0.07)$ at $\mathrm{hCB}_{2}$, which is similar to that previously published (Soethoudt et al., 2017).

Compounds 1, 2, 5-7, and 7-16 were subjected to a $10 \mu \mathrm{M}$ heterologous competition binding screen, subsequent to which those compounds which displaced more than $60 \%$ of the competing radioligand were advanced to determine binding affinity (Table 1). All cyclopentyl substituted triazines (1, 2, 5, and 6) failed to displace, or barely displaced, [ $\left.{ }^{3} \mathrm{H}\right]-\mathrm{CP} 55,940$. The three adamantanyl substituted triazines with an alkyl chain, aminohexyl-piperazinyl-12, the corresponding Boc-protected analogue 9, and the short chain aminoethyl-piperazinyl derivative 11 were moderate binders which approached but did not exceed our displacement cut-off and so $K_{i}$ values were not determined.

The remaining six compounds displaced more than $60 \%$ of the competing radioligand and were therefore advanced in our study to determine binding affinity $\left(\mathrm{K}_{\mathrm{i}}\right)$ and later characterise functionally. Of these, 16 and $\mathbf{1 5}$ had the highest affinities with $\mathrm{pK}_{\mathrm{i}} \mathrm{s}$ of $8.79( \pm 0.03)$ and 8.37 ( \pm 0.18$)$, respectively. A $\sim 100$-fold reduction in $\mathrm{hCB}_{2}$ affinity was measured for piperazinyl-7 ( $\mathrm{pK}_{\mathrm{i}} 6.38 \pm 0.16$ ) compared to methylpiperazinyl15, despite the difference of just a methyl group between the two analogues. The triazines containing a 1,2-diethoxyethane (PEG2)-piperazinyl moiety, amino-PEG2-piperazinyl-13 and the corresponding Boc-protected (10) and acetylated (14) analogues, exhibited measurable binding, however introduction of this PEG2 linker reduced binding affinity by approximately 2$3 \log$ units compared to methylpiperazinyl-15. Functional characterisation at $\mathrm{hCB}_{2}$ was therefore undertaken for $7, \mathbf{1 0}$, 13, 14, 15, and 16, as well as CP 55,940 which we utilised as a reference ligand as this was expected to be a full agonist at $\mathrm{hCB}_{2}$ in every pathway we intended to evaluate (Soethoudt et al., 2017).

We were also interested to determine whether these six compounds exhibited any $\mathrm{CB}_{1}$ orthosteric binding. A $10 \mu \mathrm{M}$ heterologous competition radioligand binding screen revealed that only 15 and 16 displaced more than $60 \%$ of $\left[{ }^{3} \mathrm{H}\right]-\mathrm{CP}$ 55,940 (0.75 nM), however neither compound produced full displacement at this concentration (Table 1).

\section{Internalisation}

$\mathrm{hCB}_{2}$ internalisation was assessed in response to a $1 \mathrm{~h}$ stimulation with $7, \mathbf{1 0}, \mathbf{1 3}, \mathbf{1 4}, \mathbf{1 5}, \mathbf{1 6}$, and CP 55,940. All compounds except 13 behaved as agonists in this pathway and this agonist-induced internalisation was concentrationdependent (Figure 1 and Table 2). CP 55,940 internalised $\sim 66 \%$ of starting surface $\mathrm{hCB}_{2}$, which was a very similar response to that observed previously stimulating $\mathrm{CB}_{2}$ with HU-308 (Grimsey et al., 2011). Efficacies were comparable 
TABLE 1 | Structures and $\mathrm{hCB}_{2}$ binding affinities for CP 55,940 and 2,4,6-trisubstituted 1,3,5-triazine analogues.

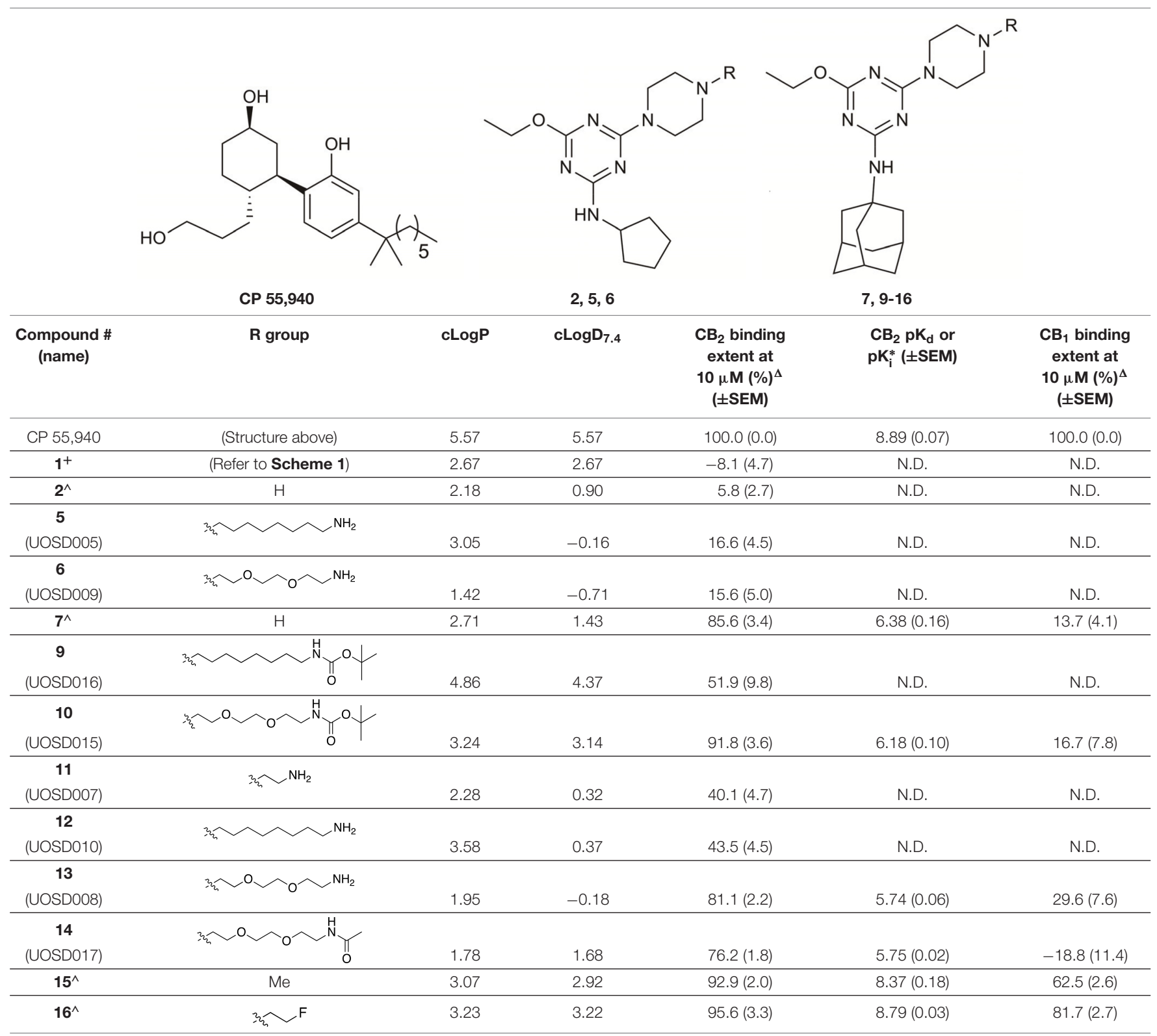

N.D., Not determined. ${ }^{*} p K_{d}$ for CP 55,940, or pK for all other compounds. ${ }^{+}$First reported in Yrjölä et al. (2013). ^First reported in Yrjölä et al. (2015). ${ }^{\Delta}$ Binding extent expressed as percentage of $\beta \mathrm{HJ}-\mathrm{CP} 55,940$ displacement.

between CP 55,940 and all compounds that induced receptor internalisation, except for $\mathbf{1 6}$ which was significantly less efficacious $(p<0.001$, one-way ANOVA). The rank order of potencies generally correlated with the rank order of binding affinity, with the exception that $\mathbf{1 5}$ had an equivalent internalisation potency as CP 55,940 despite having approximately half a log unit lower affinity. 13 appears to be a neutral antagonist in this pathway at the time point assayed as it was not significantly different from the vehicletreated condition ( $p=0.111$ at $10 \mu \mathrm{M}, t$-test). As there was no measurable efficacy for this compound, an $\mathrm{EC}_{50}$ could not be determined.

\section{Cyclic AMP (cAMP)}

The effects of 7, 10, 13, 14, 15, 16, and CP 55,940 on forskolinstimulated cAMP concentration were then investigated using a real-time CAMYEL cAMP biosensor assay (Jiang et al., 2007). Each compound, excluding 13, inhibited cAMP production (as expected for $\mathrm{CB}_{2}$ agonists) and reached maximum efficacy $\left(E_{\max }\right)$ $\sim 5$ min after drug addition. Concentration-response curves for each compound were accordingly generated at 5 min post-drug addition (Figure 2). The remainder of the time course observed (up to $30 \mathrm{~min}$ ) were unremarkable, with responses exhibiting a partial recovery towards forskolin alone. As shown in Table 2, $E_{\max }$ for all the compounds tested were similar to that of $\mathrm{CP}$ 


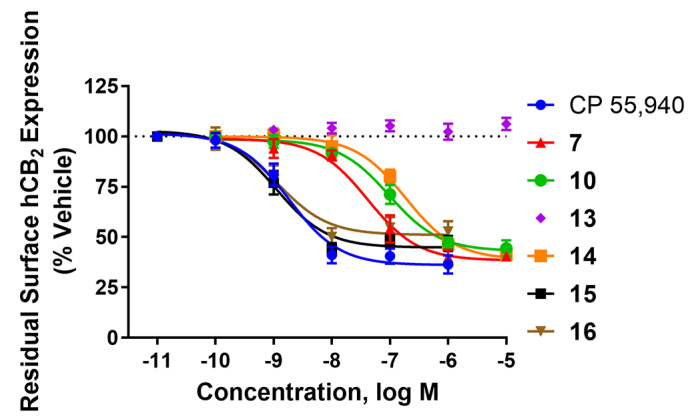

FIGURE 1 | Internalisation of $\mathrm{hCB}_{2}$ in response to CP 55,940 and 2,4,6-trisubstituted 1,3,5-triazines. Internalisation of $\mathrm{hCB}_{2}$ in $\mathrm{HEK}$ Flp-in $\mathrm{hCB}_{2}$ cells in response to a $1 \mathrm{~h}$ stimulation with varying concentrations of $\mathrm{CP}$ 55,940 or test compounds. Data are presented as mean \pm SEM from 3-4 independent experiments, and were normalised to vehicle-treated (100\%).

55,940 , with the exception of $\mathbf{1 0}$ and $\mathbf{1 4}$ which appeared to act as partial agonists $(p=0.049$ and $p=0.004$, respectively, one-way ANOVA).

To identify whether there were any non- $\mathrm{hCB}_{2}$-mediated effects on cAMP signalling, the HEK Flp-in wt line was assayed in the same manner. Application of 7, 10, 14, 15, 16, and CP 55,940 all had an effect on cAMP signalling in the HEK Flp-in wt cells, in the form of an increase in cAMP at high concentration(s) (Figure 2). At the highest concentration tested, non-hCB $\mathrm{h}_{2}$-mediated effects ranged from approximately 10 to $40 \%$ above forskolin. CP 55,940 had the least pronounced non-hCB $\mathrm{h}_{2}$ signalling profile (low potency and low efficacy), while $\mathbf{1 6}$ and $\mathbf{7}$ had the most pronounced effects. Importantly, however, the majority of compounds reached maximal apparent $\mathrm{hCB}_{2}$-mediated efficacy at a lower concentration than non-hCB $\mathrm{CB}^{-}$ mediated effects were first detected. The exceptions were 14 and 10, wherein the non-hCB $\mathrm{CB}_{2}$-mediated effects were only $\sim 5$ - to $\sim 23$-fold (respectively) less potent than the cAMP inhibition induced in $\mathrm{hCB}_{2}$-expressing cells. These non- $\mathrm{hCB}_{2}$-mediated increases in cAMP likely counteracted the $\mathrm{hCB}_{2}$-induced suppression of cAMP production, thereby blunting the apparent $E_{\max }$ of these two compounds. We therefore do not feel it is possible to conclusively determine the $\mathrm{CB}_{2}$-mediated potency or efficacy for $\mathbf{1 0}$ or $\mathbf{1 4}$ in this assay.

Amino-PEG2-piperazinyl-13 did not inhibit forskolinstimulated cAMP, but instead induced a transient concentration-dependent $\mathrm{hCB}_{2}$-mediated increase in cAMP, with a peak response time $\sim 4$ min after addition, and reaching a $E_{\max }$ of $\sim 45 \%$ above forskolin at the highest concentration assayed (Figures 3A,C and Table 2). To assess whether this compound was acting as an inverse agonist via $G \alpha_{i}$ or was stimulating cAMP production via a non-G $\alpha_{i}$ pathway, cells were pre-treated with PTX to irreversibly inactivate $G \alpha_{i}$ protein. As seen in Figure 3C, the observed cAMP signal for $\mathbf{1 3}$ was completely PTX-sensitive and thus $\mathrm{G} \alpha_{\mathrm{i}}$-mediated, suggestive of inverse agonism. SR 144528, a $\mathrm{CB}_{2}$ inverse agonist (Portier et al., 1999), was therefore assayed for comparison with 13. Stimulation with SR 144528 also resulted in a concentration-dependent increase in cAMP (Figure 3D), however an interesting point of difference between 13 and SR 144528 lies in their kinetics. As seen in Figure 3B, SR 144528 reached its $E_{\max }$ approximately 6 min after drug addition and this was maintained over the following $20 \mathrm{~min}$, whereas compound 13 had a more rapid onset and returned to the cAMP concentration induced by forskolin alone within 10-15 $\mathrm{min}$. Concentration response curves were plotted at $5 \mathrm{~min}$ for each compound. In this analysis, SR 144528 inhibited constitutive $\mathrm{G} \alpha_{\mathrm{i}}$ activity with a greater efficacy than 13 , reaching a maximum of 55.4\% ( \pm 6.89) above forskolin (vs. $44.7 \% \pm 4.6$ for 13). The increase by SR 144528 was confirmed to be PTX-sensitive (Figure 3D). Both of these compounds were also assayed in the HEK Flp-in wt line, and as seen in Figures 3C,D, did not exhibit any measurable non-hCB $\mathrm{CB}_{2}$-mediated effects.

\section{Phospho-ERK (pERK)}

The final functional pathway studied was the phosphorylation (activation) of ERK1/2. A time course experiment was first carried out for $7, \mathbf{1 0}, \mathbf{1 3}, \mathbf{1 4}, \mathbf{1 5}, \mathbf{1 6}$, and CP 55,940 which revealed transient responses that reached maxima at $4 \mathrm{~min}$ for all compounds (data

TABLE 2 | Summary data for $\mathrm{hCB}_{2}$ functional assays carried out on CP 55,940 and 2,4,6-trisubstituted 1,3,5-triazines.

\begin{tabular}{|c|c|c|c|c|c|c|c|c|c|}
\hline Compound \# & \multicolumn{3}{|c|}{ Internalisation (1 h) } & \multicolumn{3}{|c|}{ cAMP (5 min) } & \multicolumn{3}{|c|}{ pERK (4 min) } \\
\hline 7 & $7.34(0.15)$ & $-61.4(2.7)$ & 4 & $7.07(0.15)$ & $-43.0(3.0)$ & 3 & $5.74(0.05)$ & $+2.06(0.08)$ & 3 \\
\hline 10 & $7.05(0.13)$ & $-57.4(2.3)$ & 4 & $6.98(0.11)^{\Delta}$ & $-33.0(0.9)^{\Delta}$ & 3 & $5.97(0.04)$ & +10.18 (1.16) & 3 \\
\hline 13 & Not Measurable & $+6.2(3.1)^{*}$ & 3 & $6.10(0.17)$ & $+44.7(4.6)$ & 3 & $6.27(0.07)$ & $+1.22(0.13)$ & 3 \\
\hline 16 & $8.92(0.09)$ & $-50.0(2.7)$ & 4 & $8.55(0.16)$ & $-35.6(2.2)$ & 3 & $7.91(0.08)$ & $+7.63(0.25)$ & 3 \\
\hline
\end{tabular}

a Internalisation $E_{\max }$ represented as reduction (-) or increase (+) in surface expression, as a percentage of vehicle-treated control. ${ }^{b} \mathrm{CAMP} \mathrm{E}_{\max }$ represented as reduction $(-)$ or increase (+) in CAMP as a percentage of forskolin-treated (100\%) minus Vehicle-treated (0\%) controls. ${ }^{c} p E R K E_{\max }$ indicates increase in $p E R K$ as a percentage of PMA (100\%) and U0126 (0\%) controls, less Vehicle-treated control. *A concentration-response curve could not be fitted, therefore efficacy at the highest concentration tested (i.e., $10 \mu \mathrm{M}$ ) is noted instead of $E_{\text {max. }}{ }^{\Delta}$ Parameters are approximate due to the possible influence of non- $C B_{2}$-mediated effects. ${ }^{\wedge} A$ fully defined concentrationresponse curve could not be obtained, therefore this $p E C_{50}$ can only be considered approximate, and efficacy at the highest concentration tested (i.e., $10 \mu M$ ) is noted instead of $E_{\max }$. Column " $n$ " indicates the number of independent experiments performed. 

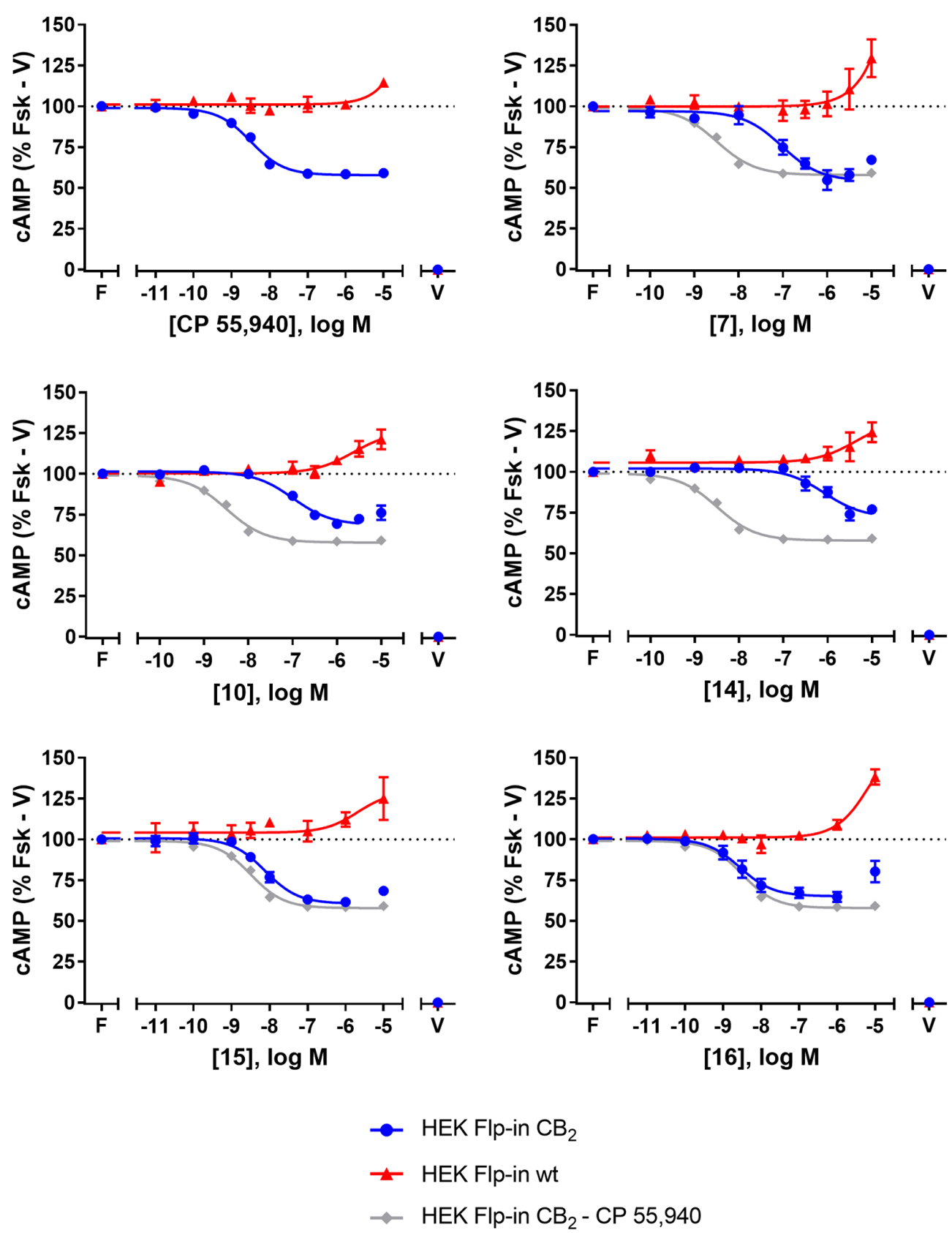

FIGURE 2 | cAMP signalling in HEK Flp-in hCB 2 and HEK Flp-in wt cells in response to CP 55,940 and 2,4,6-trisubstituted 1,3,5-triazines. Concentration-response curves for modulation of CAMP concentration in $\mathrm{HEK}$ Flp-in $\mathrm{hCB}_{2}$ and $\mathrm{HEK}$ Flp-in wt cells (showing both $\mathrm{hCB}_{2}-\mathrm{and}_{\text {non-hCB }}$-mediated effects) on stimulation with $5 \mu \mathrm{M}$ forskolin and CP 55,940 or test compounds (other than 13). Concentration-response curves were generated by plotting measurements at 5 min post-drug addition. These data were then normalised to vehicle-treated ( $\mathrm{F} ; 0 \%)$ and forskolin alone (F, Fsk; 100\%). Data are presented as mean \pm SEM from three independent experiments.

not shown). As such, concentration responses were carried out at $4 \mathrm{~min}$. Efficacies are presented as percentage response above vehicle, relative to PMA as a positive control (being a strong activator of pERK, Besson et al., 2001) and U0126 as a negative control (being a MEK/ERK pathway blocker, Favata et al., 1998). At 4 min post-drug stimulation, CP 55,940 activated pERK with an $E_{\max }$ of $10.29 \%( \pm 0.94)$ (Figure $4 \mathrm{~A}$ and Table 2). Compounds $\mathbf{1 0}$ and $\mathbf{1 5}$ had equivalent efficacies to CP 55,940. 16 activated pERK with an $E_{\max }$ of $7.63 \%$ ( \pm 0.25$)$, trending towards partial agonism, though this efficacy was not significantly different from CP 55,940 ( $p=0.053$, one-way ANOVA) (Figure 4A and Table 2). As shown in Table 2 and graphically represented in Figure 4A, 13 and 7, are weak partial agonists, activating pERK with mean $E_{\max }$ of $1.22 \%( \pm 0.13)$ and $2.06 \%( \pm 0.08)$ respectively; these were 

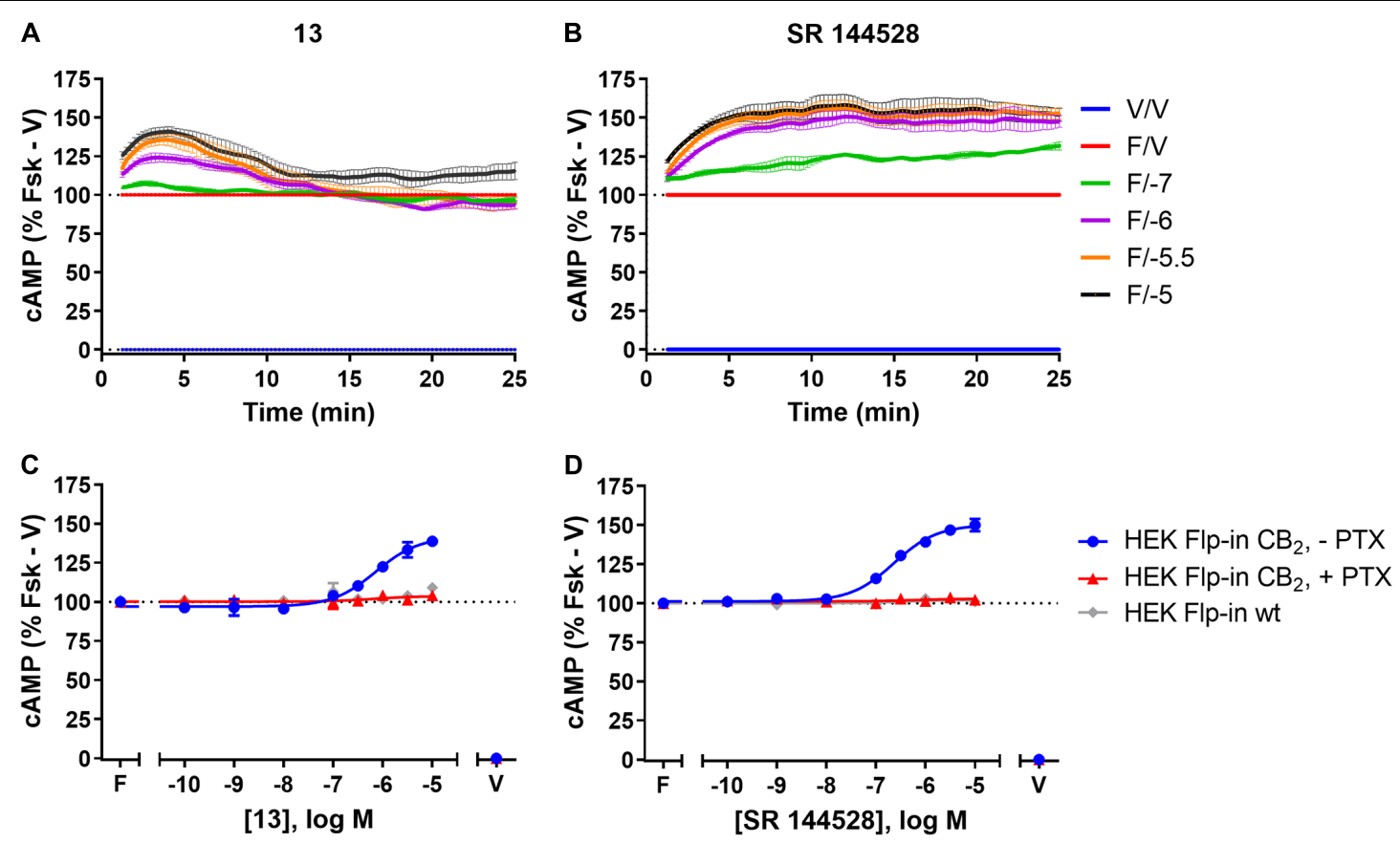

FIGURE 3 | cAMP signalling in HEK Flp-in hCB 2 and HEK Flp-in wt cells in response to $\mathbf{1 3}$ and prototypic inverse agonist, SR 144528. (A,B) Time courses for modulation of cAMP concentration by $\mathbf{1 3}$ (A) and SR 144528 (B) at active concentrations (noted in log units, in the presence of $5 \mu$ M forskolin "F/_") on HEK Flp-in $\mathrm{hCB}_{2}$ cells. Data were normalised to vehicle-treated ("VN"; 0\%) and forskolin alone ("FN"; 100\%). (C,D) Concentration-response curves for modulation of cAMP concentration by compound $\mathbf{1 3}$ (C) and SR 144528 (D) (both in the presence of $5 \mu \mathrm{M}$ forskolin) in HEK Flp-in hCB 2 cells following $16-20$ h pre-treatment in the absence or presence of PTX, or in HEK Flp-in wt cells. Concentration-response curves were generated by plotting each concentration measured at 5 min post-drug addition. These data were then normalised to vehicle-treated ( $\mathrm{F} ; 0 \%)$ and forskolin alone (F, Fsk; $100 \%)$. Data in all panels are presented as mean \pm SEM from three independent experiments.

significantly different from that of CP 55,940 ( $p<0.001$, oneway ANOVA) and vehicle ( $p=0.004$ and $p<0.001$, respectively, paired $t$-test). These assays were also carried out in HEK Flp-in wt cells at each compound's highest concentration tested to identify whether any non-specific effects on pERK activation were present; none were detected (data not shown).

To verify whether observed agonist activity was $\mathrm{G} \alpha_{\mathrm{i}}$-mediated, pERK activation was measured in response to a maximally efficacious concentration of each ligand with and without PTX pre-treatment. As compound $\mathbf{1 3}$ appeared to be an antagonist/inverse agonist in the other functional assays carried out and its efficacy in this pERK pathway was extremely low, a full concentration response was carried out in the presence of PTX for this compound. Figures 4B,C demonstrate that all the ligands' pERK responses were completely PTX-sensitive, confirming that all compounds are agonists in this pathway acting via $\mathrm{G} \alpha_{i}$.

\section{Comparison of Ligand Efficacy and Potency, and Bias Analysis}

Having measured $\mathrm{hCB}_{2}$ binding affinities and responses in three functional assays, we were interested to compare the patterns of efficacy and potency between the 2,4,6-trisubstituted 1,3,5triazine ligands and a prototypic $\mathrm{CB}_{2}$ ligand (CP 55,940), and determine whether any ligands exhibited evidence of bias between activation of these signalling pathways. As 13 was only an agonist in one pathway formal pathway bias calculations for this compound are impossible.

As an initial means of summarising and exploring our data, we compared concentration response $E_{\max }$ values (relative to the maximum measured response at any single concentration for each assay), and $\mathrm{pEC}_{50}$ values having subtracted each ligand's own measured equilibrium binding affinity $\left(\mathrm{pK}_{\mathrm{d}}\right.$ or $\mathrm{pK}_{\mathrm{i}}$ as applicable).

Firstly inspecting efficacy (Figure 5A), CP 55,940 and 15 exhibited essentially equivalent efficacy in all three pathways measured, acting as full agonists relative to the series of compounds tested and in the cell model utilised. 16 also produced an equivalent response between all three assays, acting as a partial agonist in all pathways (inducing approximately $75-80 \%$ of maximal efficacy), though as per earlier analysis this was only found to be statistically different from CP 55,940 in the internalisation pathway. $\mathbf{1 0}$ appeared to be a full agonist in both the internalisation and pERK pathways. Although slightly lesser efficacy in the CAMP assay was measured for this compound, this may have been due to the presence of non-specific effects at active concentrations [see also the section "Cyclic AMP (cAMP)"]. The efficacy profile of $\mathbf{1 4}$ is difficult to judge due to the difficulty in estimating cAMP efficacy (due to non- $\mathrm{CB}_{2}$ mediated effects), and its low potency in the pERK assay preventing reliable determination of $E_{\max }$. Very interestingly, 7 acted as a full agonist in both the internalisation and cAMP assays, however was a weak partial agonist in the pERK assay with only $36 \%$ response 

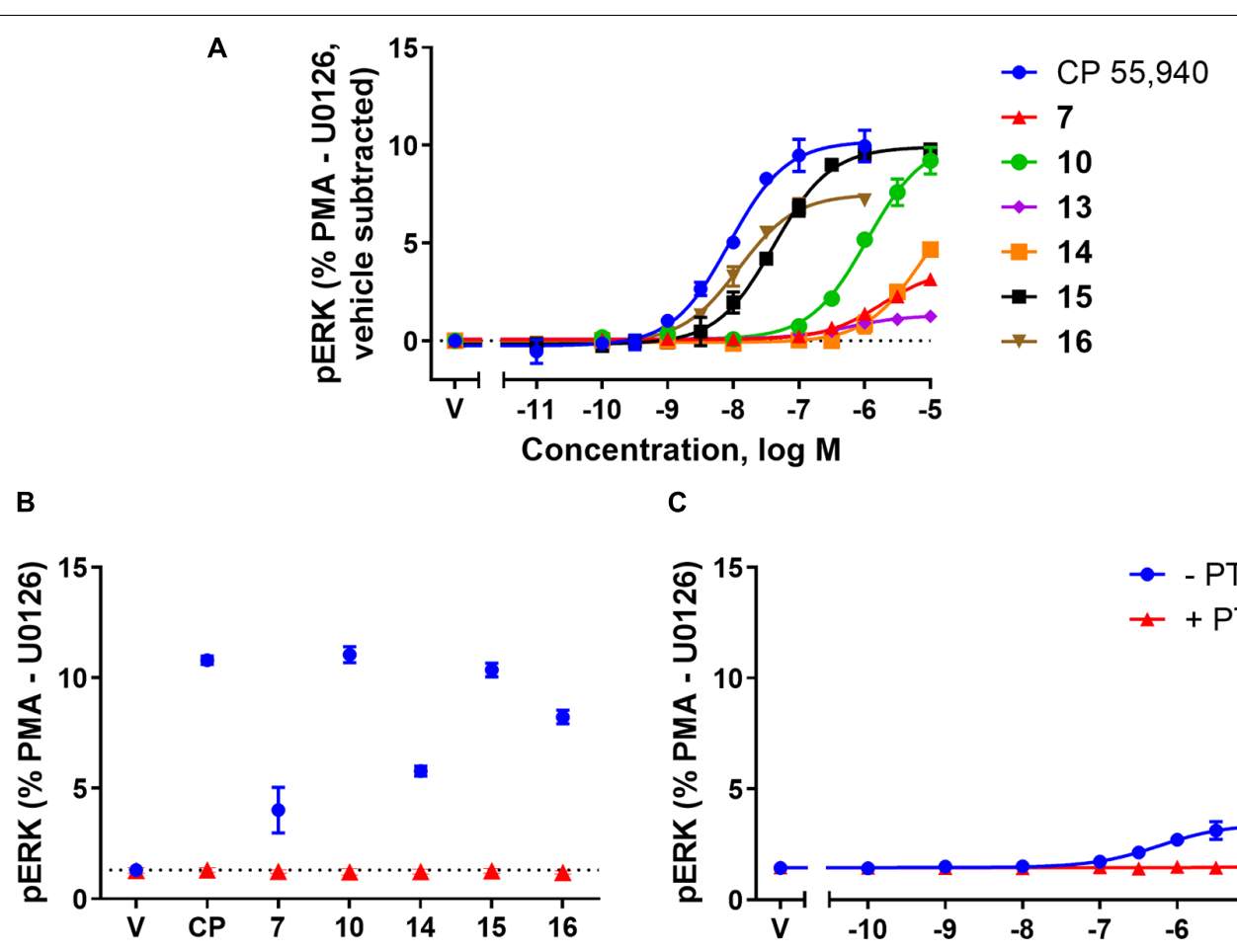

c

FIGURE 4 | pERK activation via hCB 2 in response to CP 55,940 and 2,4,6-trisubstituted 1,3,5-triazines. ERK1/2 phosphorylation (pERK) at 4 min post-drug addition in HEK Flp-in hCB 2 cells. (A) Concentration-response curves for CP 55,940 and all test compounds. (V, vehicle) (B) Response at a single concentration (1 $\mu \mathrm{M}$ for $\mathrm{CP}$ 55,940 and 16, $10 \mu \mathrm{M}$ for others) following 27-28 h pre-treatment in the absence or presence of PTX (CP, CP 55,940). Dotted line indicates average vehicle ( $)$ response. (C) Concentration-response curve for $\mathbf{1 3}$ following $27-28 \mathrm{~h}$ pre-treatment in the absence or presence of PTX. Data in all panels are presented as mean \pm SEM from three independent experiments, and normalised to U0126 (0\%) and PMA (100\%). In panel (A) the vehicle response in each experiment was then subtracted such that the vehicle condition is represented as $0 \%$.

relative to the maximal measured response across all ligands. Given that the rank order of efficacy for $\mathbf{1 6}$ versus 7 is different between the pERK pathway and the other two pathways studied (cAMP and Internalisation), this is an initial indication that there may be genuine bias away from pERK activation for 7 (e.g., Berg et al., 1998; Charfi et al., 2015).

In examining signalling assay potencies $\left(\mathrm{EC}_{50}\right)$ relative to equilibrium binding affinity (Figure 5B), we first noted that $\mathrm{CP} 55,940$ had the smallest $\mathrm{EC}_{50}$ range between all pathways. This, combined with its full efficacy in all pathways, supports its selection as a reference ligand for subsequent bias analysis (van der Westhuizen et al., 2014). CP 55,940's potency for inducing internalisation was similar to its binding affinity $(p=0.127$, oneway ANOVA), and the potency for eliciting a cAMP response was moderately $(\sim 0.4$ log units) lower than binding affinity ( $p=0.010$, one-way ANOVA). In contrast, the pERK response had a nearly 10-fold lower potency than affinity $(p<0.001$, one-way ANOVA) and approximately $0.5 \log$ unit lower potency than that for cAMP ( $p=0.007$, one-way ANOVA). This general relationship between CAMP and $\mathrm{pERK}$ potencies was consistent for all the 2,4,6-trisubstituted 1,3,5-triazines tested (other than 13). 16 exhibited a similar pattern of $\mathrm{EC}_{50}$ relative to binding affinity to CP 55,940, however other compounds deviated from this pattern.
The $\mathrm{EC}_{50}$ pattern of $\mathbf{1 5}$ was also similar to CP 55,940 for cAMP and pERK, however its propensity to induce internalisation (relative to its equilibrium binding affinity) was approximately half a $\log$ unit more potent than would be predicted based on CP 55,940 ( $p<0.001$; two-way ANOVA). The pattern for $\mathbf{1 4}$ was similar to $\mathbf{1 5}$, though it must be noted that due to its low potency we consider the cAMP and pERK parameters for this compound to be approximate. Both of these ligands therefore demonstrate some informal indication of bias towards induction of $\mathrm{hCB}_{2}$ internalisation. $\mathbf{7}$ and $\mathbf{1 0}$ also had seemingly high internalisation potencies relative to binding affinity ( $p<0.001$, two-way ANOVA), however these also exhibited greater potencies for inhibiting cAMP synthesis than would have been predicted from CP 55,940 ( $p<0.001$, two-way ANOVA), and 10 additionally induced ERK phosphorylation with a greater relative potency in comparison with CP 55,940 ( $p=0.003$, two-way ANOVA). Therefore, given that the relationship between the signalling pathway potencies (relative to binding affinity) is similar for 10 and CP 55,940 (i.e., no bias between signalling pathways is necessarily indicated), but the potencies for $\mathbf{1 0}$ are all greater than expected in comparison to $\mathrm{CP} 55,940$, a high intrinsic coupling efficiency for activating $\mathrm{CB}_{2}$ is indicated for 10. That is, half-maximal efficacy might be reached at a lower $\mathrm{hCB}_{2}$ 

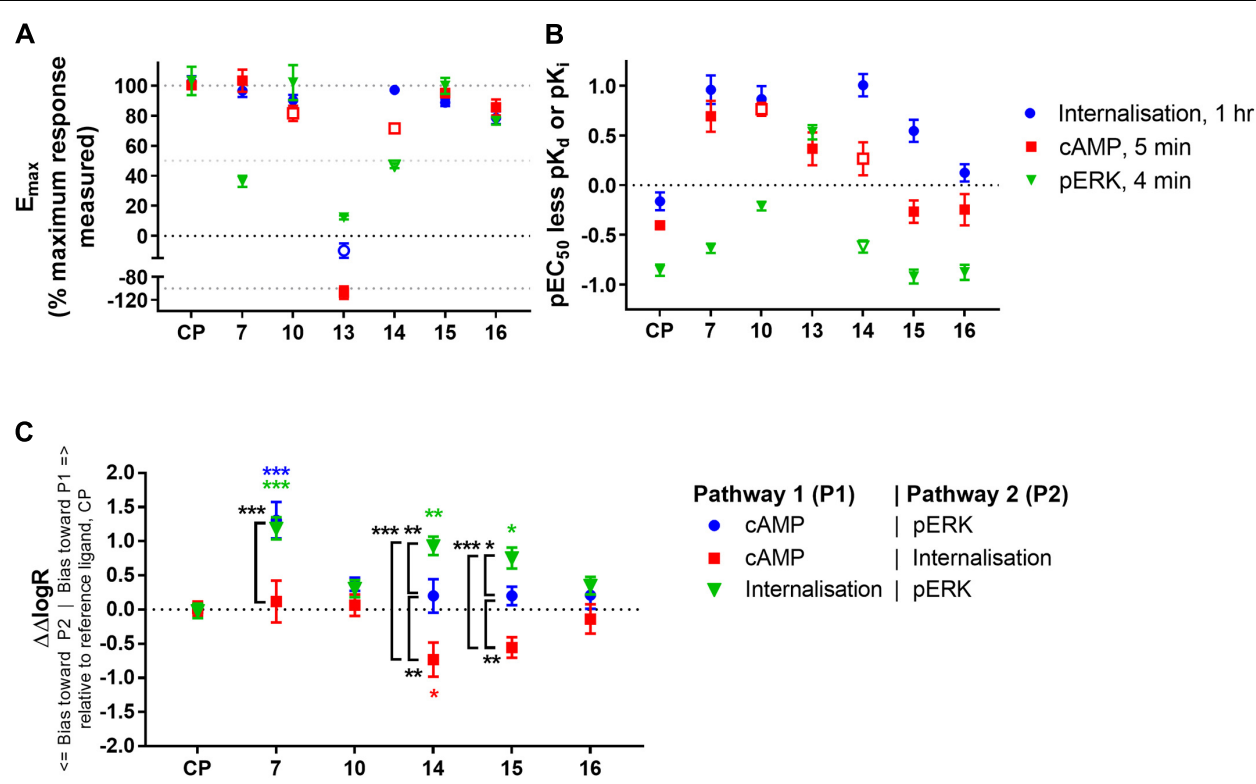

FIGURE 5 | Comparison of ligand efficacy, potency (relative to binding affinity), and signalling pathway bias for CP 55,940 and 2,4,6-trisubstituted 1,3,5-triazines. (A) Internalisation, inhibition of CAMP production and stimulation of $\mathrm{pERK} E_{\max }$ for each compound normalised to the overall maximum response measured at a single concentration in each pathway. Hollow symbols represent efficacy measures where conclusive $E_{\text {max }}$ values could not be determined; for $\mathbf{1 0}$ and $\mathbf{1 4}$ cAMP

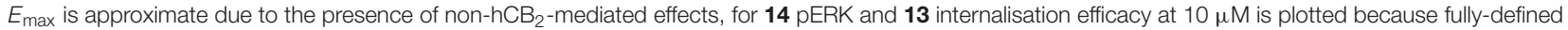

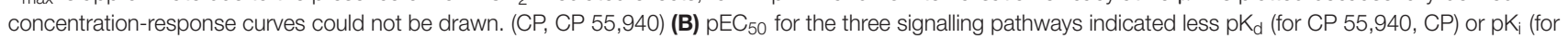
the 2,4,6-trisubstituted 1,3,5-triazines). Hollow symbols represent potency measures where conclusive EC 50 values could not be determined; for $\mathbf{1 0}$ and $\mathbf{1 4}$ cAMP $\mathrm{EC}_{50}$ is approximate due to the presence of non-hCB 2 -mediated effects, for $\mathbf{1 4} \mathrm{pERK} \mathrm{EC}_{50}$ is approximate due to its low potency. (C) Between-signalling pathway bias as represented by $\Delta \Delta \log R$ in comparison with CP 55,940 (CP) as a reference ligand. $\mathbf{1 3}$ could not be included in the bias quantitation as it is an agonist in only one pathway. The symbol "*" in colour indicates significant difference from CP 55,940 for the same bias comparison; The symbol "*" in black and white indicates significant difference for the comparison indicated by the associated bracket; significance levels as defined in the methods. Data in all panels are presented as mean \pm SEM from three independent experiments.

occupancy with 10 than would be required for half-maximal efficacy when stimulating with CP 55,940. 7 seemed to act similarly to $\mathbf{1 0}$ in terms of having apparently high coupling efficiency for activating both internalisation and cAMP (in comparison with CP 55,940), however this was less apparent for pERK.

Given the noted indications of possible bias, we proceeded to carry out formal quantitative bias analysis utilising CP 55,940 as the reference ligand (Figure 5C and Table 3). We followed the method of van der Westhuizen et al. (2014), which is based on the seminal Black and Leff operational model (Black and Leff, 1983). This approach facilitates the calculation of a "transduction coefficient" $\left(\tau / K_{A}\right)$ which is the coupling efficiency of an agonist to a signalling pathway $(\tau)$ relative to binding affinity $\left(\mathrm{K}_{\mathrm{A}}\right)$. This is calculated for each ligand in each signalling pathway and typically represented as a decimal logarithm (here referred to as $\log \mathrm{R})$. When considered relative to a reference ligand $(\Delta \log \mathrm{R})$ and compared between signalling pathways $(\Delta \Delta \log \mathrm{R})$, a measure of relative bias for activating one pathway over another is obtained. This parameter, and derived bias factor (BF, $10^{\Delta \Delta \log \mathrm{R}}$ ) which indicates fold differences in pathway activation bias, takes both potency and efficacy into account, removes system-specific factors (such as receptor expression level and capacity for signalling pathway activation), and allows for the possibility that receptor occupancy at the time point of the assay will not necessarily be the same as at equilibrium (i.e., $\mathrm{K}_{\mathrm{A}}$ is not necessarily identical to $\mathrm{K}_{\mathrm{d}}$ or $\mathrm{K}_{\mathrm{i}}$ ). " $n$ " is the transducer function slope, which links agonist concentration with the measured response.

As expected from the above exploration, compounds $\mathbf{1 6}$ and $\mathbf{1 0}$ did not demonstrate any indication of betweenpathway bias. On the other hand, 7 exhibited statistically significant bias in comparison with CP 55,940 when the pERK pathway was compared with cAMP $(p<0.0001$, BF 20.3-fold cAMP $>$ pERK) or internalisation $(p=0.0001$, BF 15.4-fold internalisation $>$ pERK). There was no bias of 7 between cAMP and internalisation $(p=0.91)$. This, combined with the strikingly partial nature of pERK activation, likely indicates a bias of 7 away from activation of pERK, though as noted above this bias seems to be reinforced by this compound's apparent ability to induce highly efficient coupling of $\mathrm{hCB}_{2}$ to internalisation and $\mathrm{cAMP}$ inhibition. Meanwhile, compounds $\mathbf{1 5}$ and $\mathbf{1 4}$ induced cAMP versus pERK with equivalent balance to CP 55,940, however were biased towards internalisation when compared with either of the other two pathways (three of four statistical comparisons to CP 55,940 were statistically significant; 15 was not statistically different from CP 55,940 in cAMP > internalisation, however a significant difference was found between $15 \Delta \Delta \log R$ s for cAMP > internalisation versus balanced pathway comparison cAMP $>$ pERK, $p=0.034$ ). 
TABLE 3 | Signalling pathway transduction ratios (logR) and transducer function slopes (" $n$ "), with between-pathway delta-delta transduction ratios ( $\Delta \Delta$ logR) and bias factors relative to reference ligand CP 55,940.

\begin{tabular}{|c|c|c|c|c|c|c|c|c|c|}
\hline \multirow[b]{2}{*}{ Compound \# } & \multicolumn{3}{|c|}{$\log R\left[\log \left(\tau / K_{A}\right)\right]( \pm S E M)$} & \multicolumn{2}{|c|}{ cAMP - pERK } & \multicolumn{2}{|c|}{ cAMP - internalisation } & \multicolumn{2}{|c|}{ Internalisation - pERK } \\
\hline & Internalisation & cAMP & pERK & $\Delta \Delta \log R( \pm S E M)$ & $\begin{array}{c}\text { Bias } \\
\text { factor }\end{array}$ & $\begin{array}{l}\Delta \Delta \log R \\
( \pm S E M)\end{array}$ & $\begin{array}{c}\text { Bias } \\
\text { factor }\end{array}$ & $\begin{array}{l}\Delta \Delta \log R \\
( \pm S E M)\end{array}$ & $\begin{array}{l}\text { Bias } \\
\text { factor }\end{array}$ \\
\hline CP 55,940 & $8.76(0.1)$ & $8.52(0.02)$ & $8.05(0.03)$ & $0.00(0.04)$ & 1.0 & $0.01(0.10)$ & 1.0 & $-0.02(0.11)$ & 1.0 \\
\hline 7 & $7.42(0.26)$ & $7.29(0.26)$ & $5.51(0.05)$ & $1.31(0.27)^{* * *}$ & 20.3 & $0.12(0.31)$ & 1.3 & $1.19(0.16)^{* * *}$ & 15.4 \\
\hline 10 & $7.09(0.10)$ & $6.90(0.10)$ & $6.06(0.02)$ & $0.37(0.10)$ & 2.4 & $0.07(0.16)$ & 1.2 & $0.31(0.13)$ & 2.0 \\
\hline 14 & $6.81(0.23)$ & $5.83(0.23)$ & $5.16(0.09)$ & $0.20(0.25)$ & 1.6 & $-0.73(0.25)^{*}$ & 0.2 & $0.93(0.13)^{* *}$ & 8.6 \\
\hline 15 & $8.92(0.09)$ & $8.12(0.09)$ & $7.45(0.10)$ & $0.20(0.13)$ & 1.6 & $-0.56(0.15)$ & 0.3 & $0.76(0.15)^{*}$ & 5.7 \\
\hline 16 & $8.90(0.19)$ & 8.52 (0.19) & $7.84(0.07)$ & $0.21(0.20)$ & 1.6 & $-0.14(0.22)$ & 0.7 & $0.35(0.13)$ & 2.2 \\
\hline$n^{\Delta}$ & $1.49(0.21)$ & $1.28(0.14)$ & $1.14(0.06)$ & & & & & & \\
\hline
\end{tabular}

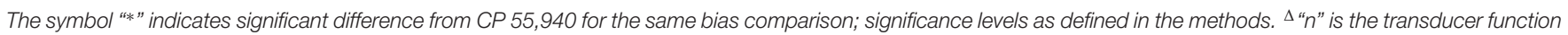
slope which was determined for each signalling pathway as a shared constraint between ligands when fitting the operational model.

\section{DISCUSSION}

In this study, thirteen 2,4,6 trisubstituted 1,3,5-triazine derivatives, comprising five previously reported compounds and eight novel compounds, were synthesised and characterised for their affinity and activity at $\mathrm{hCB}_{2}$.

Comparison of competitive orthosteric radioligand binding revealed that in all three cases an adamantanyl group was highly favoured over a cyclopentyl group when other substituents were held the same ( 7 vs. 2,12 vs. 5 , and 13 vs. 6). This trend was also observed in previous reports (e.g., Yrjölä et al., 2015), where adamantanyl derivatives were more potent in a GTP $\gamma \mathrm{S}$ assay than the corresponding cyclopentyl triazine derivatives in all examples reported.

Compounds 7, 15, and 16 have previously been published as potent $\mathrm{hCB}_{2}$ agonists (compounds " 8 ," "6," and " 9 " from Yrjölä et al., 2015), however no $\mathrm{hCB}_{2}$ binding data was reported. The highest affinity compound in our study (16) differed from the next most potent (15) by the presence of a fluoroethyl instead of methyl group on the piperazine nitrogen, which conferred a nearly half-log increase in affinity. Piperazinyl-7 had approximately 100-fold lower affinity than methylpiperazinyl15, despite the only difference between these compounds being hydrogen versus methyl on the piperazine nitrogen. Along with the methyl versus hydrogen size difference, a reason for this significant change in $\mathrm{CB}_{2}$ binding might be because 7 is likely ionised to a much higher extend at physiological $\mathrm{pH}$ in comparison with $\mathbf{1 5}$. We tested seven adamantanyl-ethoxytriazines with varying linkers from the piperazine ring with a view to identifying linker derivatives which retain affinity and functional activity. We found that incorporation of a hexyl chain $(9,12)$ was not well tolerated in this position and considerably reduced (though did not completely prevent) binding to $\mathrm{hCB}_{2}$, whereas use of a PEG2 linker $(\mathbf{1 0}, \mathbf{1 3}, \mathbf{1 4})$ was more successful in retaining $\mathrm{hCB}_{2}$ affinity.

While we did not investigate binding of these compounds to $\mathrm{hCB}_{1}$ in depth, $\mathbf{1 5}$ and $\mathbf{1 6}$ were indicated to be somewhat $\mathrm{CB}_{2}$-selective in that these were relatively high affinity at $\mathrm{CB}_{2}$ and a high concentration only partially displaced $\left[{ }^{3} \mathrm{H}\right]$ CP 55,940 at $\mathrm{CB}_{1}$. The prior report of these compounds indicated approximately 1000 to 10,000 -fold functional GTP $\gamma S$ selectivity for $\mathrm{CB}_{2}$ versus $\mathrm{CB}_{1}$ (Yrjölä et al., 2015). None of the other compounds tested $(7,10,13,14)$ exhibited considerable orthosteric binding to $\mathrm{CB}_{1}$ at $10 \mu \mathrm{M}$ indicating that these are likely also $\mathrm{CB}_{2}$-selective.

We then proceeded to investigate the function of $7,10,13,14$, 15 , and $\mathbf{1 6}$ at $\mathrm{hCB}_{2}$. Firstly we made a few general observations regarding potency shifts between assays for the compound series. Internalisation tended to exhibit the greatest potencies, typically approximately $0.4 \log$ units higher than for CAMP (other than two exceptions discussed below). pERK usually had the lowest potencies of the three signalling assays tested; $0.8 \mathrm{log}$ units lower than CAMP on average. Given that the cAMP and pERK pathways were measured at very similar time points (5 and $4 \mathrm{~min}$, respectively) and under equivalent assay conditions, it seems unlikely that the reduced $\mathrm{pERK}$ potencies were indicative of different degrees of binding occupancy at this time point, and instead may point to lower coupling efficiency of $\mathrm{hCB}_{2}$ to this pathway. Alternatively, or perhaps in addition, this could be indicative of a large capacity for activation and detection of ERK phosphorylation in comparison with cAMP flux and $\mathrm{hCB}_{2}$ internalisation in our model system. Indeed, our measured efficacies in the pERK pathway were extremely small relative to our positive control PMA-induced response (up to $\sim 10 \%$ ) and we have previously measured approximately four times greater $\mathrm{G}_{\mathrm{i}}$ receptor-mediated $\mathrm{pERK}$ responses in a $\mathrm{HEK} \mathrm{hCB}_{1}$ cell line (Finlay et al., 2017). Furthermore, substantial receptor reserve in the cAMP pathway has been reported previously, wherein fewer than $50 \%$ of receptors were apparently required to be occupied in order to produce a 50\%-maximal response therefore manifesting in high potency responses (Finlay et al., 2017). That study was performed in an analogous model system to ours; HEK cells expressing a lower concentration of $\mathrm{hCB}_{1}$ than the expression level of $\mathrm{hCB}_{2}$ in the HEK cell line utilised in this study, therefore our $\mathrm{hCB}_{2}$ cell line could exhibit even more receptor reserve than the earlier-studied $\mathrm{CB}_{1}$ cell line. CP 55,940 was measured to have the highest binding affinity of the compounds tested, acted as a full agonist in all three signalling pathways, and exhibited the smallest range of activation potencies between the pathways, all of which support selection of CP 55,940 as a reference ligand 
for comparison with previously uncharacterised compounds (van der Westhuizen et al., 2014).

The highest affinity triazine, $\mathbf{1 6}$, had a very similar affinity and functional potencies to CP 55,940 with no evidence of biased agonism. Despite this, $\mathbf{1 6}$ appeared to act as a partial agonist in all functional assays we investigated ( $\sim 80 \%$ of maximum effect measured across all compounds), and this was consistent with prior published GTP $\gamma \mathrm{S}$ data ( $\sim 70 \%$ of maximum measured activity, Yrjölä et al., 2015). This may imply that although the $16 \mathrm{hCB}_{2}$ binding pocket clearly overlaps that for CP 55,940, the spectrum of $\mathrm{hCB}_{2}$ conformation(s) facilitated by $\mathbf{1 6}$ binding could be slightly different, perhaps resulting in the receptor spending proportionally less time in active conformation(s).

The next highest affinity compound studied, 15, acted as a full agonist in all pathways measured (including a previously published GTP $\gamma S$ assay, Yrjölä et al., 2015). Therefore, while the presence of a methyl group (15) instead of a fluoroethyl (16) on the piperazine nitrogen resulted in a somewhat lower affinity, the methyl group in $\mathbf{1 5}$ was more conducive to producing full efficacy. Interestingly, although 15 did not show any indication of bias between activation of cAMP and pERK (relative to CP 55,940), the potency of $\mathbf{1 5}$ for inducing internalisation was greater than expected and this culminated in significant pathway bias towards internalisation. $\mathbf{1 4}$ had the lowest affinity of all the compounds studied and as such parameter measurements were less definitively identified, however the profile of $\mathbf{1 4}$ seemed most similar to $\mathbf{1 5}$ and bias towards internalisation was also indicated. It therefore seems likely that these compounds facilitate stabilisation of $\mathrm{hCB}_{2}$ in conformation(s) that promote internalisation without considerable influence on acute cAMP or pERK pathways. Although receptor activation is typically considered a prerequisite for internalisation, this is not necessarily $\mathrm{G}$ protein dependent, as has previously been shown for $\mathrm{CB}_{2}$ (whereby receptor internalisation was not PTX-sensitive, Atwood et al., 2012), as well as for the $\mu$-opioid receptor [where morphine barely internalises the receptor but still induces $G$ protein-gated inwardly-rectifying potassium (GIRK) channel activation, Bradbury et al., 2009]. As such, it is not surprising that these pathways could be modulated independently. Given that desensitisation and phosphorylation are generally accepted prerequisites for the onset of internalisation it might have been predicted that the time courses of cAMP inhibition and pERK activation may have been altered (e.g., earlier or more rapid desensitisation), however we did not observe any such change over the time courses monitored. Alternatively, this bias may have been made evident by the more chronic nature of the internalisation assay (measured at $1 \mathrm{~h}$ ) in comparison with the cAMP and pERK assays ( 5 and $4 \mathrm{~min}$, respectively). For example it was recently demonstrated that the direction of apparent agonist bias can be reversed depending on the time point assayed and that this may be associated with ligands' dissociation kinetics (Herenbrink et al., 2016). In other words, drugs with slower off rates may produce bias for pathways assayed at later time points, as receptor occupancy will be higher. Regardless of mechanism, as arrestin recruitment is frequently associated with receptor phosphorylation and internalisation (Krupnick and Benovic, 1998) it would be pertinent to investigate arrestin recruitment with these ligands in future studies. It would also be particularly interesting to investigate whether the increased propensity to internalise the receptor has any consequence on medium- to long-term cannabinoid responsiveness; for example, non-canonical signalling from endosomes might be influenced, and modulation of receptor recycling versus degradation would influence cellular re-sensitisation.

In comparison with CP 55,940, 10 exhibited high potencies in all three signalling pathways relative to its binding affinity. That is, this ligand was seemingly able to induce maximal functional effects while occupying fewer receptors than CP 55,940 . The simplest explanation for this phenomenon is that once bound to $\mathrm{hCB}_{2} \mathbf{1 0}$ is more effective at stabilising the active conformation(s) of $\mathrm{hCB}_{2}$ than $\mathrm{CP} 55,940$. This would imply that "receptor reserve" must be present for all three signalling pathways we studied, and the high intrinsic activity of compound $\mathbf{1 0}$ manifests as leftward potency shifts relative to receptor occupancy. Ligand $\mathbf{1 0}$ therefore has the potential to be a greater efficacy $\mathrm{hCB}_{2}$ agonist than CP 55,940 if tested in a model system with sufficiently low $\mathrm{hCB}_{2}$ expression and/or large capacity for generating/reporting signalling responses (Luttrell, 2014). For internalisation, measuring an earlier time point may also have been illuminating in this regard. This theory would certainly be interesting to verify in a follow-up study. It is also plausible that this ligand possesses a relatively rapid $\mathrm{hCB}_{2}$ on-rate which manifests as greater assay potency due to more efficient acute binding of $\mathbf{1 0}$ to $\mathrm{hCB}_{2}$ in comparison with the other ligands tested. Although we did not detect differences in the onset of cAMP or pERK signalling between any of the ligands studied (which could have supported this theory), it is possible that either our assays were not sufficiently temporally sensitive to reveal such a difference, or the rates of ligand-receptor association for the range of ligands tested were all sufficient to reach the maximum rate of pathway activation for our model system. An additional hypothesis could be that an increased local concentration of ligand at the plasma membrane - for example if the membrane was acting as a reservoir or "sink" (Vauquelin, 2016) - might manifest as high apparent intrinsic coupling efficiency. However, this ligand was not predicted to have notably unique physicochemical properties in the context of the other triazines we pharmacologically characterised, and given the increased polarity in comparison with "traditional" cannabinoids would be less likely to accumulate in this manner than our reference ligand, CP 55,940. Taken together, it seems that $\mathbf{1 0}$ acts as a balanced high intrinsic efficacy agonist for activating $\mathrm{hCB}_{2}$ in the signalling pathways we studied.

7 exhibited a particularly interesting signalling profile. In our model system, 7 was a full agonist and produced a similar potency:affinity profile to high intrinsic efficacy agonist $\mathbf{1 0}$ in the cAMP and internalisation assays suggesting that it too likely acts with high intrinsic efficacy in these pathways. However, it was a weak partial agonist in the pERK pathway, producing only $\sim 36 \%$ of the maximal measured response across all ligands and exhibiting significant bias away from pERK relative to CP 55,940 and the other two signalling pathways measured. This is somewhat in agreement with previously reported data wherein 7 elicited $\sim 60 \%$ of maximum measured activity in a GTP $\gamma S$ 
assay (Yrjölä et al., 2015). While this bias is exciting to identify and has the potential to produce unique downstream functional effects in comparison with balanced ligands, the mechanism driving this bias is not immediately obvious. In particular, partial agonism in GTP $\gamma \mathrm{S}$ and PTX-sensitivity of ERK phosphorylation do not reconcile well with high intrinsic activation of $G \alpha_{\mathrm{i} / \mathrm{o}^{-}}$ mediated adenylate cyclase inhibition, although similar bias towards adenylate cyclase inhibition in comparison with pERK and GTP $\gamma \mathrm{S}$ has been observed for opioid ligands activating the $\mu$-opioid receptor (Thompson et al., 2015). Clearly more in-depth study of this ligand is warranted in order to further probe the mechanism producing this pattern of signalling bias at $\mathrm{hCB}_{2}$. However, to our knowledge this ligand is unique in that it represents the first identification of a $\mathrm{hCB}_{2}$ agonist with bias away from PERK, whereas two prior studies have identified ligands with bias towards pERK versus cAMP (Shoemaker et al., 2005; Soethoudt et al., 2017). Given the highly context-dependent nature of activation of the ERK pathway on cellular function the potential clinical relevance of a ligand with reduced propensity to stimulate ERK phosphorylation such as $\mathbf{7}$ is difficult to predict. Nonetheless, 7 would certainly be an interesting candidate for in vivo study to determine functional effects in comparison with un- or differentially-biased ligands, which may well be illuminating in efforts towards development of $\mathrm{CB}_{2}$-targeted therapeutics.

The most intriguing findings of our study came about in the functional characterisation of $\mathbf{1 3}$ which has a primary amine at the end of the PEG2 linker. Surprisingly this behaved extremely differently to all the other compounds tested, acting as a neutral antagonist in the internalisation pathway, an unconventional transient inverse agonist for adenylate cyclase inhibition, and an extremely weak partial agonist for pERK activation. Note that despite appearing to act as a neutral antagonist in the internalisation pathway, inverse agonism wouldn't necessarily be able to be detected at this time point in this assay (which would have manifested in this assay as an apparent increase above the vehicle-treated condition, as described in Grimsey et al., 2011), nor perhaps extremely weak partial agonism. We therefore cannot conclude whether this compound is acting as an inverse agonist, neutral antagonist, or very weak partial agonist in this pathway. While examples of compounds acting as both an agonist and antagonist via different signal transducers at the same receptor have been reported (e.g., Kilts et al., 2002; De Deurwaerdere et al., 2004; Corbisier et al., 2017), including for $\mathrm{CB}_{2}$ (Schuehly et al., 2011; Dhopeshwarkar and Mackie, 2016), the fact that the responses in both signalling assays were PTXsensitive (and thus both downstream of $\mathrm{CB}_{2}$ coupling to $\mathrm{G} \alpha_{\mathrm{i}}$ ) is tantalisingly conflicting, as it implies that this compound is acting as both a weak agonist and inverse agonist at $\mathrm{CB}_{2}$ via the same $\mathrm{G}$ protein.

The cAMP kinetic signature of $\mathbf{1 3}$ was also unique in that inverse agonism was very transient, in contrast with a typical inverse agonist (SR 144528) which exhibited sustained inverse agonism over the entire time course of the assay. It is vaguely feasible, particularly given the fairly low potency of $\mathbf{1 3}$, that this interesting functional pattern could have been produced as a result of the presence of trace impurity present in our synthesised
13 sample, however, the identity of $\mathbf{1 3}$ was fully characterised by NMR and HRMS, and the purity of the sample was 100\% by analytical HPLC (as described in the section "Chemistry"). Relatedly, 13 exhibited no apparent non- $\mathrm{CB}_{2}$-mediated effects in HEK cells in the pathways we measured. One explanation for the transient inverse agonism could be instability of $\mathbf{1 3}$ in assay buffer, however this seems highly unlikely given the time course of cAMP inverse agonism was unaffected by different lengths of time in solution prior to the start of the assay (data not shown). The primary amine of $\mathbf{1 3}$ is a nucleophilic functional group however it would be highly ionised at physiological $\mathrm{pH}$, thereby making reaction with an electrophile unlikely. Furthermore, there is no apparent strong electrophile present in the cAMP assay conditions, nor anything that would appear different in these terms between the different signalling pathway assays. While there is potential for metabolism of any of the compounds tested $\mathbf{1 3}$ does not stand out as being more likely to act as a substrate than the others. It is also unlikely that $\mathbf{1 3}$ could be undergoing $N$-glucuronidation given HEK cells are usually found to lack glucuronosyltransferase activity (e.g., Southwood et al., 2007). We therefore conclude that the kinetic signature observed for $\mathbf{1 3}$ is highly likely to be a genuine characteristic of its effect on $\mathrm{CB}_{2}$.

The authors are not aware of findings in the literature analogous to this transient inverse agonism (although it should be noted that to date very few studies have utilised time courses when monitoring inverse agonism, and so transient responses might not have been detected even if present). However, we have postulated some theories with potential to explain the unique functional profile of 13 , which would be interesting to address in future studies. One hypothesis is that $\mathbf{1 3}$ is acting as a bitopic ligand, i.e., it has affinity/activity for both orthosteric and allosteric sites (Kamal and Jockers, 2009), a phenomenon which has previously been reported for the muscarinic receptors (Steinfeld et al., 2007; Valant et al., 2008). Indeed, we have previously reported $\mathrm{CB}_{1}$ allosteric modulators to have unique temporal influences on inhibition of cAMP production (Cawston et al., 2013, 2015). Given that $\mathbf{1 0}$ and $\mathbf{1 4}$ possesses a similar PEG2 linker as 13, the PEG2 linker in itself seems unlikely to be primarily responsible for exerting the observed functional pattern, although the presence of an acetyl versus tert-butoxy versus primary amine at the linker terminus would likely have an effect on ligand-receptor interactions. Whether via orthosteric-induced conformational changes or allosterism it is indeed feasible that small changes in ligand structure can correspond to major structural movements at the cytosolic face of the receptor and consequently affect signalling considerably (Shonberg et al., 2013). Alternatively, or perhaps in concert with this theory, the unique cAMP temporal fingerprint could arise as a consequence of the small ERK activation (or activation of other signalling pathways not yet investigated) inducing a downstream effect such as stimulating a post-translational modification (PTM) on $\mathrm{CB}_{2}$. Following initial stabilisation of a predominantly inactive conformation by $\mathbf{1 3}$ (notwithstanding extremely weak pERK activation), perhaps such a PTM could shift the conformational equilibrium away from the inactive state and facilitate the receptor re-gaining the ability to inhibit 
adenylate cyclase, thereby producing the apparent loss of inverse agonism and return to constitutive inhibition of adenylate cyclase. GPCR constitutive activity has been shown to increase by mutation of particular residues (Pauwels and Wurch, 1998), as such it is feasible that PTMs of specific residues could also induce the same effect. Similarly, influences on dimerisation or other protein-protein interactions (e.g., Glass and Felder, 1997; Bakker et al., 2004), or receptor transit between membrane microdomains (e.g., Jiao et al., 2005), may be involved. Another possible factor in this unique signalling fingerprint is the physicochemical properties of 13. Of the compounds we characterised functionally, $\mathbf{1 3}$ was calculated as having the most polar $c \log \mathrm{P}$ and $\mathrm{CLog}_{7.4}$. Polar compounds may have an alternative mode of access to $\mathrm{hCB}_{2}$ compared to more lipophilic cannabinoids which likely enter via the lipid bilayer (Hurst et al., 2010). 13 could perhaps therefore have a different mode of access to the receptor compared with the remainder of the compounds. It is also tempting to hypothesise that, due to its increased polarity, 13 might not have access to intracellular $\mathrm{CB}_{2}$ or that access may be relatively slow. If intracellular $\mathrm{CB}_{2}$ usually contributes to signalling when cell-permeable ligands are utilised, an inability or delay to activating intracellular $\mathrm{CB}_{2}$ may profoundly influence the apparent signalling profile. Of course, there are many factors that contribute to the cellular permeability of a compound, degree of polarity and ionisation being just two. It would certainly be interesting to directly investigate cell permeability of $\mathbf{1 3}$ in future, potentially utilising assays such as the parallel artificial membrane permeability assay (PAMPA). Finally, physicochemical properties might also influence ligand partitioning within the plasma membrane (e.g., lipid rafts) and thereby perhaps 13 could interact with a unique subset of $\mathrm{CB}_{2}$ and/or a changing subset over time (Barnett-Norris et al., 2005; Vauquelin and Packeu, 2009).

In this study we functionally characterised a set of thirteen 2,4,6-trisubstituted 1,3,5-triazines, all of which are considerably more polar than most cannabinoids studied to date, and eight of which were novel. Compounds 7, 14 (UOSD017) and 15 exhibited interesting bias profiles ( 7 biased away from pERK activation, 14 and 15 biased towards internalisation) and one compound exhibited high potency in all signalling pathways measured relative to affinity (10 [UOSD015]). Meanwhile, 13 (UOSD008) produced a completely unique functional profile at $\mathrm{hCB}_{2}$, acting as a mixed agonist/inverse agonist. It will

\section{REFERENCES}

Atwood, B. K., and Mackie, K. (2010). CB2: a cannabinoid receptor with an identity crisis. Br. J. Pharmacol. 160, 467-479. doi: 10.1111/j.1476-5381.2010.00729.x

Atwood, B. K., Wager-Miller, J., Haskins, C., Straiker, A., and Mackie, K. (2012). Functional selectivity in $\mathrm{CB}(2)$ cannabinoid receptor signaling and regulation: implications for the therapeutic potential of CB(2) Ligands. Mol. Pharmacol. 81, 250-263. doi: 10.1124/mol.111.074013

Bab, I., and Ofek, O. (2011). Targeting the CB2 cannabinoid receptor in osteoporosis. Expert. Rev. Endocrinol. Metab. 6, 135-138. doi: 10.1586/eem.11.2

Bakker, R. A., Casarosa, P., Timmerman, H., Smit, M. J., and Leurs, R. (2004). Constitutively active $\mathrm{Gq} / 11$-coupled receptors enable signaling by co-expressed G(i/o)-coupled receptors. J. Biol. Chem. 279, 5152-5161. doi: 10.1074/jbc. M309200200 be interesting to further characterise the functional activity of these ligands and investigate the mechanisms underlying these apparent biases in future studies. 16 was found to have a similar bias profile to that of CP 55,940 (whereby it was relatively balanced across all pathways measured) however, due to its greater polarity, would likely have a more favourable pharmacokinetic profile. It would accordingly be particularly interesting to compare the activity of these compounds in vivo. Some of our novel compounds included the incorporation of linkers for potential secondary reporter or fluorophore attachment, but require further optimisation since none of our novel compounds rivalled the affinity of 15, although 10 (UOSD015) which includes a Boc-protected PEG2-piperazinyl moiety is a promising candidate for further modification. This study has characterised a number of $\mathrm{CB}_{2}$ ligands with greater polarity than traditional cannabinoid agonists and that exhibit moderate to high affinity and unique signalling patterns. As such, these could form the basis of a ligand "toolbox" for further $\mathrm{CB}_{2}$ in vitro and in vivo studies, and potentially be useful in the development of peripherally-restricted cannabinoid ligands.

\section{AUTHOR CONTRIBUTIONS}

CO contributed to the experimental and project design, carried out the majority of the experiments and analysis, wrote the first draft of the manuscript, and prepared all figures and tables. $\mathrm{SdlH}$ synthesised and purified the compounds. YS carried out the pERK experiments and associated analysis. MG contributed to project design and interpretation. AV designed the novel compounds, supervised the synthesis, and contributed to project design and interpretation. NG designed the project and analysis, oversaw all elements, and obtained the funding. All authors reviewed and edited the manuscript.

\section{FUNDING}

This research was funded by a Royal Society of New Zealand Marsden Fast-Start project grant (UOA1507). CO was supported by a University of Auckland Doctoral Scholarship. YS was supported by Dean's International Doctoral Scholarship, Faculty of Medical and Health Sciences, The University of Auckland.

Barnett-Norris, J., Lynch, D., and Reggio, P. H. (2005). Lipids, lipid rafts and caveolae: Their importance for GPCR signaling and their centrality to the endocannabinoid system. Life Sci. 77, 1625-1639. doi: 10.1016/j.lfs.2005. 05.040

Berg, K. A., Maayani, S., Goldfarb, J., Scaramellini, C., Leff, P., and Clarke, W. P. (1998). Effector pathway-dependent relative efficacy at serotonin type 2A and $2 \mathrm{C}$ receptors: evidence for agonist-directed trafficking of receptor stimulus. Mol. Pharmacol. 54, 94-104. doi: 10.1124/mol.54.1.94

Besson, A., Davy, A., Robbins, S. M., and Yong, V. W. (2001). Differential activation of ERKs to focal adhesions by PKC epsilon is required for PMA-induced adhesion and migration of human glioma cells. Oncogene 20, 7398-7407. doi: 10.1038/sj.onc. 1204899

Black, J. W., and Leff, P. (1983). Operational models of pharmacological agonism. Proc. R. Soc. Lond. B Biol. Sci. 220, 141-162. doi: 10.1098/rspb.1983.0093 
Bouaboula, M., Poinot-Chazel, C., Marchand, J., Canat, X., Bourrie, B., RinaldiCarmona, M., et al. (1996). Signaling pathway associated with stimulation of CB2 peripheral cannabinoid receptor. Involvement of both mitogen-activated protein kinase and induction of Krox-24 expression. Eur. J. Biochem. 237, 704-711. doi: 10.1111/j.1432-1033.1996.0704p.x

Bouaboula, M., Rinaldi, M., Carayon, P., Carillon, C., Delpech, B., Shire, D., et al. (1993). Cannabinoid-receptor expression in human leukocytes. Eur. J. Biochem. 214, 173-180. doi: 10.1111/j.1432-1033.1993.tb1 7910.x

Bradbury, F. A., Zelnik, J. C., and Traynor, J. R. (2009). G Protein independent phosphorylation and internalization of the $\delta$-opioid receptor. J. Neurochem. 109, 1526-1535. doi: 10.1111/j.1471-4159.2009.06082.x

Brailoiu, G. C., Deliu, E., Marcu, J., Hoffman, N. E., Console-Bram, L., Zhao, P., et al. (2014). Differential activation of intracellular versus plasmalemmal CB2 cannabinoid receptors. Biochemistry 53, 4990-4999. doi: 10.1021/bi500632a

Castaneda, J. T., Harui, A., and Roth, M. D. (2017). Regulation of cell surface CB2 receptor during human B Cell activation and differentiation. J. Neuroimmune Pharmacol. 12, 544-554. doi: 10.1007/s11481-017-9744-7

Cawston, E. E., Connor, M., Di Marzo, V., Silvestri, R., and Glass, M. (2015). Distinct temporal fingerprint for cyclic adenosine Monophosphate (cAMP) signaling of indole-2-carboxamides as allosteric modulators of the cannabinoid receptors. J. Med. Chem. 58, 5979-5988. doi: 10.1021/acs.jmedchem.5b00579

Cawston, E. E., Redmond, W. J., Breen, C. M., Grimsey, N. L., Connor, M., and Glass, M. (2013). Real-time characterization of cannabinoid receptor 1 (CB1) allosteric modulators reveals novel mechanism of action. Br. J. Pharmacol. 170, 893-907. doi: 10.1111/bph.12329

Cencioni, M. T., Chiurchiu, V., Catanzaro, G., Borsellino, G., Bernardi, G., Battistini, L., et al. (2010). Anandamide suppresses proliferation and cytokine release from primary human T-lymphocytes mainly via CB2 receptors. PLoS One 5:e8688. doi: 10.1371/journal.pone.0008688

Charfi, I., Audet, N., Tudashki, H. B., and Pineyro, G. (2015). Identifying ligandspecific signalling within biased responses: focus on delta opioid receptor ligands. Br. J. Pharmacol. 172, 435-448. doi: 10.1111/bph.12705

Corbisier, J., Huszagh, A., Gales, C., Parmentier, M., and Springael, J. Y. (2017). Partial agonist and biased signaling properties of the synthetic enantiomers J113863/UCB35625 at chemokine receptors CCR2 and CCR5. J. Biol. Chem. 292, 575-584. doi: 10.1074/jbc.M116.757559

Correa, F., Hernangomez-Herrero, M., Mestre, L., Loria, F., Docagne, F., and Guaza, C. (2011). The endocannabinoid anandamide downregulates IL-23 and IL-12 subunits in a viral model of multiple sclerosis: evidence for a cross-talk between IL-12p70/IL-23 axis and IL-10 in microglial cells. Brain Behav. Immun. 25, 736-749. doi: 10.1016/j.bbi.2011.01.020

De Deurwaerdere, P., Navailles, S., Berg, K. A., Clarke, W. P., and Spampinato, U. (2004). Constitutive activity of the serotonin2C receptor inhibits in vivo dopamine release in the rat striatum and nucleus accumbens. J. Neurosci. 24, 3235-3241. doi: 10.1523/jneurosci.0112-04.2004

De Laurentiis, A., Araujo, H. A., and Rettori, V. (2014). Role of the endocannabinoid system in the neuroendocrine responses to inflammation. Curr. Pharm. Des. 20, 4697-4706. doi: 10.2174/13816128206661401302 12957

Dhopeshwarkar, A., and Mackie, K. (2016). Functional selectivity of CB2 cannabinoid receptor ligands at a canonical and noncanonical pathway. J. Pharmacol. Exp. Ther. 358, 342-351. doi: 10.1124/jpet.116.232561

Favata, M. F., Horiuchi, K. Y., Manos, E. J., Daulerio, A. J., Stradley, D. A., Feeser, W. S., et al. (1998). Identification of a novel inhibitor of mitogen-activated protein kinase kinase. J. Biol. Chem. 273, 18623-18632. doi: 10.1074/jbc.273. 29.18623

Felder, C. C., Joyce, K. E., Briley, E. M., Mansouri, J., Mackie, K., Blond, O., et al. (1995). Comparison of the pharmacology and signal transduction of the human cannabinoid CB1 and CB2 receptors. Mol. Pharmacol. 48, 443-450.

Finlay, D. B., Cawston, E. E., Grimsey, N. L., Hunter, M. R., Korde, A., Vemuri, V. K., et al. (2017). Gas signalling of the CB1 receptor and the influence of receptor number. Br. J. Pharmacol. 174, 2545-2562. doi: 10.1111/bph.13866

Finlay, D. B., Joseph, W. R., Grimsey, N. L., and Glass, M. (2016). GPR18 undergoes a high degree of constitutive trafficking but is unresponsive to N-Arachidonoyl Glycine. PeerJ 4:e1835. doi: 10.7717/peerj.1835

Galiegue, S., Mary, S., Marchand, J., Dussossoy, D., Carriere, D., Carayon, P., et al. (1995). Expression of central and peripheral cannabinoid receptors in human immune tissues and leukocyte subpopulations. Eur. J. Biochem. 232, 54-61. doi: 10.1111/j.1432-1033.1995.tb20780.x

Glass, M., and Felder, C. C. (1997). Concurrent stimulation of cannabinoid CB1 and dopamine D2 receptors augments cAMP accumulation in striatal neurons: evidence for a Gs linkage to the CB1 receptor. J. Neurosci. 17, 5327-5333. doi: 10.1523/JNEUROSCI.17-14-05327.1997

Grimsey, N. L., Goodfellow, C. E., Dragunow, M., and Glass, M. (2011). Cannabinoid receptor 2 undergoes Rab5-mediated internalization and recycles via a Rab11-dependent pathway. Biochim. Biophys. Acta 1813, 1554-1560. doi: 10.1016/j.bbamcr.2011.05.010

Grimsey, N. L., Narayan, P. J., Dragunow, M., and Glass, M. (2008). A novel highthroughput assay for the quantitative assessment of receptor trafficking. Clin. Exp. Pharmacol. Physiol. 35, 1377-1382. doi: 10.1111/j.1440-1681.2008.04991.x

Herenbrink, C. K., Sykes, D. A., Donthamsetti, P., Canals, M., Coudrat, T., Shonberg, J., et al. (2016). The role of kinetic context in apparent biased agonism at GPCRs. Nat. Commun. 7:10842. doi: 10.1038/ncomms10842

Huestis, M. A. (2007). Human cannabinoid pharmacokinetics. Chem. Biodivers. 4, 1770-1804. doi: 10.1002/cbdv.200790152

Hurst, D. P., Grossfield, A., Lynch, D. L., Feller, S., Romo, T. D., Gawrisch, K., et al. (2010). A lipid pathway for ligand binding is necessary for a cannabinoid G protein-coupled receptor. J. Biol. Chem. 285, 17954-17964. doi: 10.1074/jbc. M109.041590

Jiang, L. I., Collins, J., Davis, R., Lin, K.-M., DeCamp, D., Roach, T., et al. (2007). Use of a cAMP BRET Sensor to Characterize a Novel Regulation of cAMP by the Sphingosine 1-Phosphate/G(13) Pathway. J. Biol. Chem. 282, 10576-10584. doi: 10.1074/jbc.M609695200

Jiao, X., Zhang, N., Xu, X., Oppenheim, J. J., and Jin, T. (2005). Ligandinduced partitioning of human CXCR1 chemokine receptors with lipid raft microenvironments facilitates G-protein-dependent signaling. Mol. Cell. Biol. 25, 5752-5762. doi: 10.1128/mcb.25.13.5752-5762.2005

Kamal, M., and Jockers, R. (2009). Bitopic ligands: all-in-one orthosteric and allosteric. F1000 Biol. Rep. 1:77. doi: 10.3410/B1-77

Kano, M., Ohno-Shosaku, T., Hashimotodani, Y., Uchigashima, M., and Watanabe, M. (2009). Endocannabinoid-mediated control of synaptic transmission. Physiol. Rev. 89, 309-380. doi: 10.1152/physrev.00019.2008

Karsak, M., Cohen-Solal, M., Freudenberg, J., Ostertag, A., Morieux, C., Kornak, U., et al. (2005). Cannabinoid receptor type 2 gene is associated with human osteoporosis. Hum. Mol. Genet. 14, 3389-3396. doi: 10.1093/hmg/ ddi 370

Kilts, J. D., Connery, H. S., Arrington, E. G., Lewis, M. M., Lawler, C. P., Oxford, G. S., et al. (2002). Functional selectivity of dopamine receptor agonists. II. Actions of dihydrexidine in D2L receptor-transfected MN9D cells and pituitary lactotrophs. J. Pharmacol. Exp. Ther. 301, 1179-1189. doi: 10.1124/jpet.301.3. 1179

Kishimoto, S., Muramatsu, M., Gokoh, M., Oka, S., Waku, K., and Sugiura, T. (2005). Endogenous cannabinoid receptor ligand induces the migration of human natural killer cells. J. Biochem. 137, 217-223. doi: 10.1093/jb/mvi021

Kleyer, J., Nicolussi, S., Taylor, P., Simonelli, D., Furger, E., Anderle, P., et al. (2012). Cannabinoid receptor trafficking in peripheral cells is dynamically regulated by a binary biochemical switch. Biochem. Pharmacol. 83, 1393-1412. doi: 10.1016/ j.bcp.2012.02.014

Krupnick, J. G., and Benovic, J. L. (1998). The role of receptor kinases and arrestins in G protein-coupled receptor regulation. Annu. Rev. Pharmacol. Toxicol. 38, 289-319. doi: 10.1146/annurev.pharmtox.38.1.289

Liu, X., Testa, B., and Fahr, A. (2011). Lipophilicity and its relationship with passive drug permeation. Pharm. Res. 28, 962-977. doi: 10.1007/s11095-0100303-7

Luttrell, L. M. (2014). Minireview: More than just a hammer: ligand "bias" and pharmaceutical discovery. Mol. Endocrinol. 28, 281-294. doi: 10.1210/me.20131314

Ma, L., Jia, J., Liu, X., Bai, F., Wang, Q., and Xiong, L. (2015). Activation of murine microglial N9 cells is attenuated through cannabinoid receptor CB2 signaling. Biochem. Biophys. Res. Commun. 458, 92-97. doi: 10.1016/j.bbrc.2015. 01.073

Marsicano, G., and Lutz, B. (2006). Neuromodulatory functions of the endocannabinoid system. J. Endocrinol. Invest. 29(Suppl.), 27-46.

McGilveray, I. J. (2005). Pharmacokinetics of cannabinoids. Pain Res. Manag. 10(Suppl. A), 15A-22A. doi: 10.1155/2005/242516 
Morales, P., Hernandez-Folgado, L., Goya, P., and Jagerovic, N. (2016). Cannabinoid receptor 2 (CB2) agonists and antagonists: a patent update. Expert Opin. Ther. Pat. 26, 843-856. doi: 10.1080/13543776.2016.1193157

Motulsky, H. J., and Christopoulos, A. (2003). ). Fitting Models to Biological Data using Linear and Nonlinear Regression. A Practical Guide to Curve Fitting. San Diego CA: GraphPad Software Inc.

Odan, M., Ishizuka, N., Hiramatsu, Y., Inagaki, M., Hashizume, H., Fujii, Y., et al. (2012). Discovery of S-777469: an orally available CB2 agonist as an antipruritic agent. Bioorg. Med. Chem. Lett. 22, 2803-2806. doi: 10.1016/j.bmcl.2012.02.072

Ofek, O., Karsak, M., Leclerc, N., Fogel, M., Frenkel, B., Wright, K., et al. (2006). Peripheral cannabinoid receptor, CB2, regulates bone mass. Proc. Natl. Acad. Sci. U.S.A. 103, 696-701. doi: 10.1073/pnas.0504187103

Pauwels, P. J., and Wurch, T. (1998). Review: amino acid domains involved in constitutive activation of G-protein-coupled receptors. Mol. Neurobiol. 17, 109-135. doi: 10.1007/BF02802027

Portier, M., Rinaldi-Carmona, M., Pecceu, F., Combes, T., Poinot-Chazel, C., Calandra, B., et al. (1999). SR 144528, an antagonist for the peripheral cannabinoid receptor that behaves as an inverse agonist. J. Pharmacol. Exp. Ther. 288, 582-589.

Schuehly, W., Paredes, J. M., Kleyer, J., Huefner, A., Anavi-Goffer, S., Raduner, S., et al. (2011). Mechanisms of osteoclastogenesis inhibition by a novel class of biphenyl-type cannabinoid $\mathrm{CB}(2)$ receptor inverse agonists. Chem. Biol. 18, 1053-1064. doi: 10.1016/j.chembiol.2011.05.012

Shaffer, J. P. (1986). Modified sequentially rejective multiple test procedures. J. Am. Stat. Assoc. 81, 826-831. doi: 10.2307/2289016

Shoemaker, J. L., Ruckle, M. B., Mayeux, P. R., and Prather, P. L. (2005). Agonistdirected trafficking of response by endocannabinoids acting at CB2 receptors. J. Pharmacol. Exp. Ther. 315, 828-838. doi: 10.1124/jpet.105.089474

Shonberg, J., Herenbrink, C. K., López, L., Christopoulos, A., Scammells, P. J., Capuano, B., et al. (2013). A structure-activity analysis of biased agonism at the dopamine D2 receptor. J. Med. Chem. 56, 9199-9221. doi: 10.1021/jm401318w

Soethoudt, M., Grether, U., Fingerle, J., Grim, T. W., Fezza, F., de Petrocellis, L., et al. (2017). Cannabinoid CB2 receptor ligand profiling reveals biased signalling and off-target activity. Nat. Commun. 8:13958. doi: 10.1038/ ncomms13958

Southwood, H. T., DeGraaf, Y. C., Mackenzie, P. I., Miners, J. O., Burcham, P. C., and Sallustio, B. C. (2007). Carboxylic acid drug-induced DNA nicking in HEK293 cells expressing human UDP-glucuronosyltransferases: Role of acyl glucuronide metabolites and glycation pathways. Chem. Res. Toxicol. 20, 1520-1527. doi: 10.1021/tx700188x

Steinfeld, T., Mammen, M., Smith, J. A., Wilson, R. D., and Jasper, J. R. (2007). A novel multivalent ligand that bridges the allosteric and orthosteric binding sites of the M2 muscarinic receptor. Mol. Pharmacol. 72, 291-302. doi: 10.1124/ mol.106.033746

Stoddart, L. A., Kilpatrick, L. E., Briddon, S. J., and Hill, S. J. (2015). Probing the pharmacology of $\mathrm{G}$ protein-coupled receptors with fluorescent ligands. Neuropharmacology 98, 48-57. doi: 10.1016/j.neuropharm.2015.04.033

Thompson, G. L., Lane, J. R., Coudrat, T., Sexton, P. M., Christopoulos, A., and Canals, M. (2015). Biased agonism of endogenous opioid peptides at the $\mu-$ opioid receptor. Mol. Pharmacol. 88, 335-346. doi: 10.1124/mol.115.098848

Valant, C., Gregory, K. J., Hall, N. E., Scammells, P. J., Lew, M. J., Sexton, P. M., et al. (2008). A novel mechanism of $G$ protein-coupled receptor functional selectivity. Muscarinic partial agonist $\mathrm{McN}-\mathrm{A}-343$ as a bitopic orthosteric/allosteric ligand. J. Biol. Chem. 283, 29312-29321. doi: 10.1074/jbc. M803801200

van der Stelt, M., Cals, J., Broeders-Josten, S., Cottney, J., van der Doelen, A. A., Hermkens, M., et al. (2011). Discovery and Optimization of 1-(4-(Pyridin2-yl)benzyl)imidazolidine-2,4-dione derivatives as a novel class of selective cannabinoid CB2 receptor agonists. J. Med. Chem. 54, 7350-7362. doi: 10.1021/ jm200916p

van der Westhuizen, E. T., Breton, B., Christopoulos, A., and Bouvier, M. (2014). Quantification of ligand bias for clinically relevant beta2-adrenergic receptor ligands: implications for drug taxonomy. Mol. Pharmacol. 85, 492-509. doi: $10.1124 / \mathrm{mol} .113 .088880$

Vauquelin, G. (2016). Cell membranes. and how long drugs may exert beneficial pharmacological activity in vivo. Br. J. Clin. Pharmacol. 82, 673-682. doi: 10. 1111/bcp. 12996

Vauquelin, G., and Packeu, A. (2009). Ligands, their receptors and plasma membranes. Mol. Cell. Endocrinol. 311, 1-10. doi: 10.1016/j.mce.2009. 07.022

Velasco, G., Sanchez, C., and Guzman, M. (2012). Towards the use of cannabinoids as antitumour agents. Nat. Rev. Cancer 12, 436-444. doi: 10.1038/nrc 3247

Wright, K., Rooney, N., Feeney, M., Tate, J., Robertson, D., Welham, M., et al. (2005). Differential expression of cannabinoid receptors in the human colon: cannabinoids promote epithelial wound healing. Gastroenterology 129, 437-453. doi: 10.1016/j.gastro.2005.05.026

Wright, K. L., Duncan, M., and Sharkey, K. A. (2008). Cannabinoid CB2 receptors in the gastrointestinal tract: a regulatory system in states of inflammation. Br. J. Pharmacol. 153, 263-270. doi: 10.1038/sj.bjp.0707486

Yrjölä, S., Kalliokoski, T., Laitinen, T., Poso, A., Parkkari, T., and Nevalainen, T. (2013). Discovery of novel cannabinoid receptor ligands by a virtual screening approach: further development of 2,4,6-trisubstituted 1,3,5-triazines as CB2 agonists. Eur. J. Pharm. Sci. 48, 9-20. doi: 10.1016/j.ejps.2012.10.020

Yrjölä, S., Sarparanta, M., Airaksinen, A. J., Hytti, M., Kauppinen, A., PasonenSeppänen, S., et al. (2015). Synthesis, in vitro and in vivo evaluation of 1,3,5triazines as cannabinoid CB2 receptor agonists. Eur. J. Pharm. Sci. 67, 85-96. doi: 10.1016/j.ejps.2014.11.003

Zhu, X., Finlay, D. B., Glass, M., and Duffull, S. B. (2018). An evaluation of the operational model when applied to quantify functional selectivity. Br. J. Pharmacol. 175, 1654-1668. doi: 10.1111/bph.14171

Ziring, D., Wei, B., Velazquez, P., Schrage, M., Buckley, N. E., and Braun, J. (2006). Formation of B and T cell subsets require the cannabinoid receptor CB2. Immunogenetics 58, 714-725. doi: 10.1007/s00251-006-0138-x

Conflict of Interest Statement: The authors declare that the research was conducted in the absence of any commercial or financial relationships that could be construed as a potential conflict of interest.

Copyright (c) 2018 Oyagawa, de la Harpe, Saroz, Glass, Vernall and Grimsey. This is an open-access article distributed under the terms of the Creative Commons Attribution License (CC BY). The use, distribution or reproduction in other forums is permitted, provided the original author(s) and the copyright owner(s) are credited and that the original publication in this journal is cited, in accordance with accepted academic practice. No use, distribution or reproduction is permitted which does not comply with these terms. 